\title{
WestVirginiaUniversity
}

THE RESEARCH REPOSITORY @ WVU

Graduate Theses, Dissertations, and Problem Reports

2016

\section{Microfluidic Based Hydrate Permeability System: Design and Construction}

\author{
Matthew Tacker
}

Follow this and additional works at: https://researchrepository.wvu.edu/etd

\section{Recommended Citation}

Tacker, Matthew, "Microfluidic Based Hydrate Permeability System: Design and Construction" (2016). Graduate Theses, Dissertations, and Problem Reports. 6762.

https://researchrepository.wvu.edu/etd/6762

This Thesis is protected by copyright and/or related rights. It has been brought to you by the The Research Repository @WVU with permission from the rights-holder(s). You are free to use this Thesis in any way that is permitted by the copyright and related rights legislation that applies to your use. For other uses you must obtain permission from the rights-holder(s) directly, unless additional rights are indicated by a Creative Commons license in the record and/ or on the work itself. This Thesis has been accepted for inclusion in WVU Graduate Theses, Dissertations, and Problem Reports collection by an authorized administrator of The Research Repository @ WVU. For more information, please contact researchrepository@mail.wvu.edu. 


\title{
Microfluidic Based Hydrate Permeability System: Design and Construction
}

\section{Matthew Tacker}

\author{
Thesis submitted \\ to the Benjamin M. Statler College of \\ Engineering and Mineral Resources \\ at West Virginia University
}

in partial fulfillment of the requirements for the degree of

Master of Science in

Chemical Engineering

\author{
Brian Anderson, Ph.D., Chair \\ Yong Yang, Ph.D. \\ Charter Stinespring, Ph.D. \\ Department of Chemical Engineering
}

Morgantown, West Virginia

2016

Keywords: Methane Hydrate Microfluidic Permeability

Copyright 2016 Matthew Tacker 


\title{
Abstract \\ Microfluidic Based Hydrate Permeability System: Design and Construction
}

\author{
Matthew Tacker
}

Methane hydrates represent a vast and untapped fossil fuel resource underlying large portions of the world's artic continental surfaces and sub-sea continental shelves. These hydrates are crystalline solids that consist of methane molecules surrounded by cages of interacting water molecules, similar to ice. Methane hydrates occur naturally, where temperature and pressure conditions favor their formation. In order to utilize these resources, methods must be developed to determine the conditions most favorable to hydrate extraction. One important condition is permeability and how it is affected by hydrates. Due to the difficulty and cost of field studies, the study of laboratory-synthesized hydrates is favored. The purpose of this research is to develop a microfluidic-chip-based model to study the formation and dissociation of methane hydrates. The chosen microfluidic chip mimics a porous media, allowing permeability studies to be performed. This use of a microfluidic chip also allows real-time visualization of hydrate formation, and accurate analysis to determine hydrate saturation levels generated in the model. Peltier plates and PID controllers add temperature control to the model to allow for profiling of hydrate formation and permeability under different experimental conditions. This model is unique in that it allows for a simultaneous correlation between permeability and hydrate saturation levels, a feature not previously available in laboratory-based hydrate models. 


\section{Acknowledgements}

First I would like to thank Dr. Brian Anderson for giving me the opportunity to develop this project with great autonomy. He allowed me to design and build this system from scratch with only a desire for the end product.

Secondly Terry Ryan for guiding me through my crazy schemes. Being the sounding board for my ideas, and providing much needed guidance, experinence, and friendship. I could not have done this without his help.

Dr. Yongkoo Seol for providing me the opportunity to receive an ORISE fellowship. Without his support, and materials this project would have never been completed.

Dr. Stiller for support and great stories. Though I was not working for his laboratory he was always there to provide mature insight.

Lastly I want to thank my lovely wife Danyel Tacker, who has constantly pushed me to be a better person. I would not be the person I am today if it were not for her support and affection. 


\section{Table of Contents}

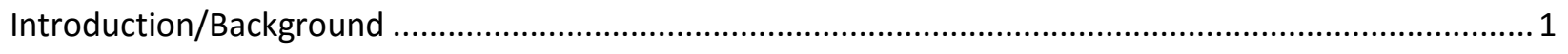

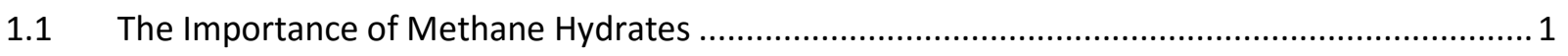

1.2 Challenges Associated With Methane Hydrate Research...................................................... 1

1.3 Darcy's Law Applications to Microfluidics ............................................................................... 2

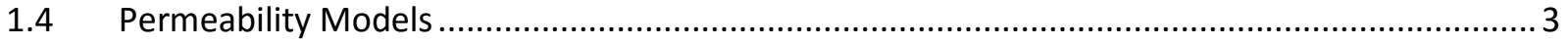

1.5 Predictive Modeling of Methane Hydrate Resources ........................................................... 4

1.6 Review of Prior Hydrate Permeability Studies .................................................................... 6

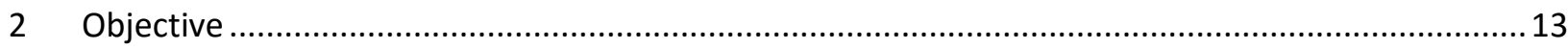

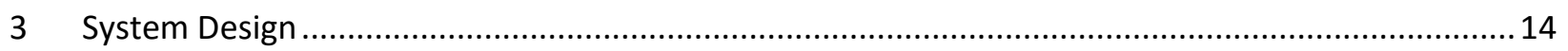

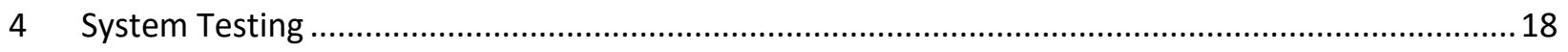

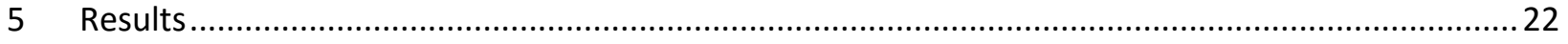

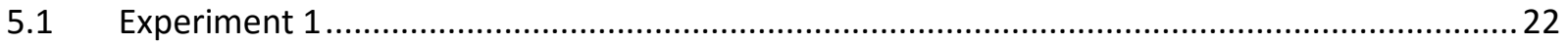

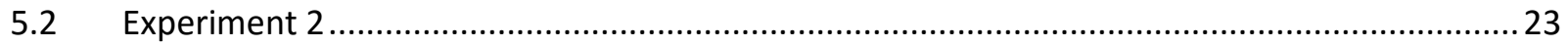

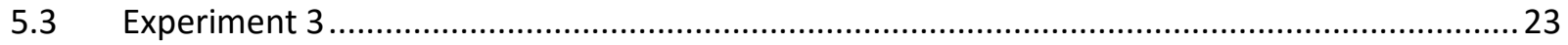

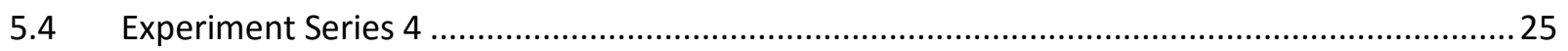

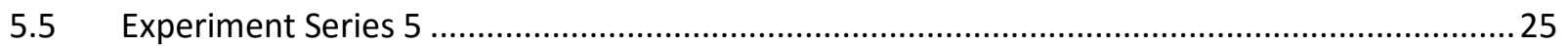

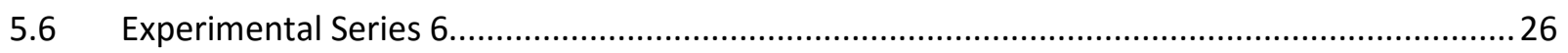

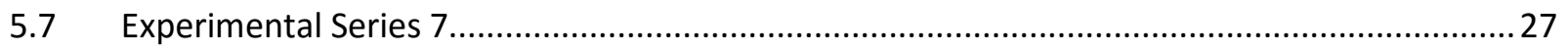

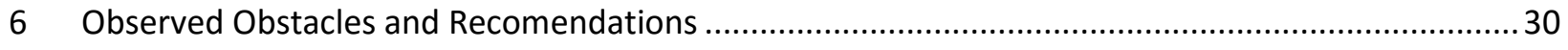

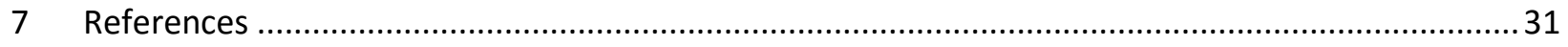




\section{Table of Figures}

1. Methane Hydrate Structure I 512 cage (King, 2014) ................................................................. 1

2. Comparison of models and experimental data of the relative water permeability as a function of

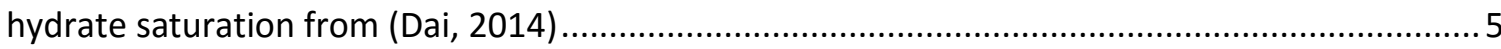

3. Comparison of experimental and calculated production when different relative permeability curves are used from (Sakamoto et al, 2009) ........................................................................ 5

4. a) Microfluidic network chip, b) fluid permeation into the network from (Berejnov et al, 2008) . 6

5. Wetting properties and corresponding network dynamics from (Berejnov et al, 2008) ...............6

6. Conceptual map of the process to produce a "Reservoir-on-a-Chip" from (Bera et al, 2013) ........7

7. Schematic of the experimental set-up for porosity and permeability measurements from (Joseph et al, 2013)

8. a) network 1 contains 2000 pores and 6000 throats, b) network 2 contains 3000 pores and 9000 throats, c) network 3 contains 3000 pores and 9000 throats with larger throat volume, and d) network 46000 pores and 20000 throats from (Joseph et al, 2013) ........................................ 8

9. Hydrate formation $(\mathrm{H})$ and dyed liquid $(\mathrm{L})$ from (Tohidi et al, 2001)........................................ 9

10. Time lapse images of dissociation of methane hydrate. $(\mathrm{PH})$ particulate hydrate crystals, $(\mathrm{FH})$ faceted hydrate crystals, $\left(L_{w}\right)$ liquid water, and $\left(V_{g}\right)$ gaseous methane from (Ohmura et al, 2008)

11. CT images showing hydrate saturation from (Ryan, 2012) ..................................................... 11

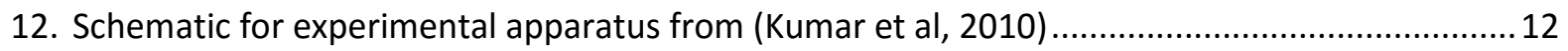

13. Dolomite microfluidic chip design details from (Dolomite, 2015)............................................. 14

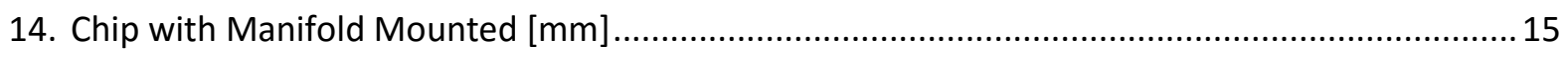

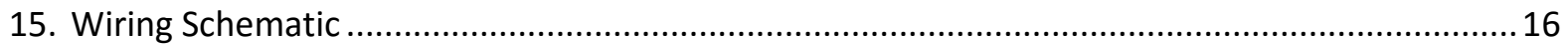

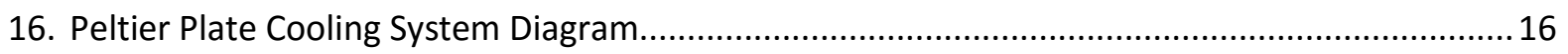

17. Fluidics for Flow Modeling ............................................................................................... 17

18. Complete system containing (from left to right) the temperature control bath, microscope, microfluidic chip, humidity control chamber, solid state relays, PID controllers, and data logging

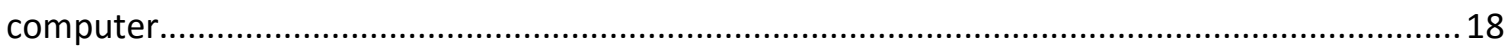

19. Ziess Stemi-2000 microscope and Infinity X-32 camera imaging the chip through the humidity

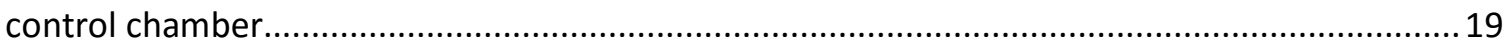

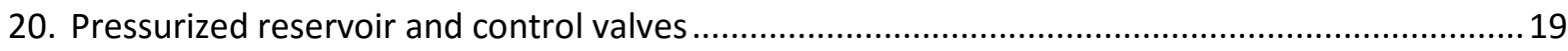

21. Chip flooded with dye stained THF/water solution in humidity control box with and inlet of dry

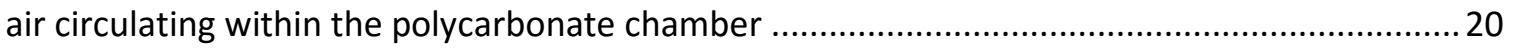

22. Solid State Relays (SSR) power switches for Peltier plates ..................................................... 20

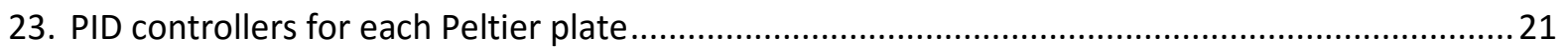

24. Live data logging of temperature across the chip and a live image of the chip ........................... 21

25. Plot of water permeability test, initial experiment to determine the flow characteristics of the

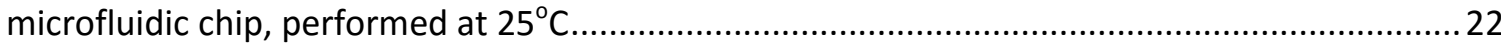

26. Frozen water crystals that have excluded the methyl blue dye .................................................. 25

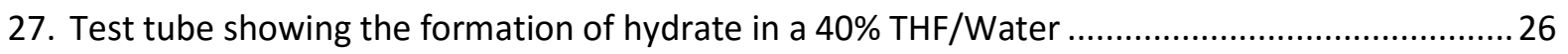

28. Close up of hydrate formed in two vials of $40 \%$ THF/Water solution. ........................................27

29. Completely flooded chip showing consistent dye distribution .................................................28

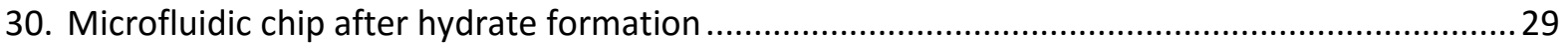




\section{Nomenclature}

$\begin{array}{ll}\Delta P & \text { Pressure Difference } \\ \mu \mathrm{m} & \text { Micrometer } \\ 2 \mathrm{D} & \text { Two Dimensions } \\ 3 \mathrm{D} & \text { Three Dimensions } \\ A & \text { Cross Sectional Area of Flow } \\ \mathrm{CO}_{2} & \text { Carbon Dioxide } \\ \mathrm{CT} & \text { Computer Topography } \\ \mathrm{DC} & \text { Direct Current } \\ \mathrm{FIB}-\mathrm{SEM} & \text { Focused lon Beam-Scanning Electron Microscopy } \\ k_{\text {act }} & \text { Actual Permeability } \\ k_{\text {intrinsic }} & \text { Intrinsic Permeability } \\ k_{\text {intrinsic }} & \text { Intrinsic Permeability } \\ \mathrm{mL} & \text { Milliliter } \\ \mathrm{mm} & \text { Millimeter } \\ \mathrm{m}^{2} & \text { Square Meter } \\ \mathrm{m}^{3} & \text { Cubic Meter } \\ \mathrm{PDMS} & \text { Polydimethylsiloxane } \\ \mathrm{PEEK} & \text { Polyether Ether Ketone } \\ \mathrm{PID} & \text { Proportional-Integral-Derivative controller } \\ Q & \text { Volumetric Flow Rate } \\ S_{h} & \text { Hydrate Saturation } \\ \mathrm{SSR} & \text { Solid State Relay } \\ \mathrm{TEC} & \text { Thermo Electric Cooling } \\ \text { THF } & \text { Tetrahydrofuran } \\ \text { w:w } & \text { Weight-by-weight ratio for solution concentration } \\ L & \text { Flow Length } \\ k & \text { Coefficient of Permeability } \\ n & \text { Archie Saturation Exponent } \\ \mu & \text { Dynamic Viscosity } \\ { }^{\circ} \mathrm{C} & \text { Degree Celsius } \\ & \end{array}$




\section{Introduction/Background}

\subsection{The Importance of Methane Hydrates}

Methane hydrates represent a vast and untapped fossil fuel resource underlying large portions of the world's artic continental surfaces and sub-sea continental shelves. Various estimates of hydrate gas resources range from 3 to 120 quadrillion $\mathrm{m}^{3}$ globally. For reference, 1 quadrillion $\mathrm{m}^{3}$ is the amount of gas consumed by the United State in 1000 years at current rates. By comparison, the largest estimate for conventional gas reserves worldwide is 0.15 quadrillion $\mathrm{m}^{3}$ methane. (Makogon, 2010)

Methane hydrate is a crystalline solid that consists of a methane molecule surrounded by a cage of interacting water molecules (Figure 1 , King 2014). Thus, methane hydrate is similar to ice and occurs naturally in subsurface deposits, where temperature and pressure conditions favor its formation. If methane hydrate is removed from this temperature and pressure environment, its structure destabilizes. For this reason, methane hydrate deposits are difficult to study; they cannot be drilled and cored like other subsurface materials, because when they are brought to the surface (where pressure is decreased and temperature rises) they will lose their structure. Thus, if one desires to study undisturbed methane hydrate from a natural deposit, precise control of pressure and

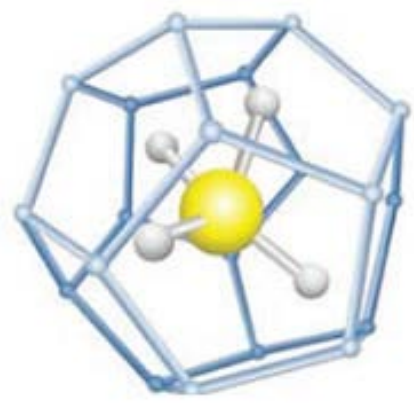

Figure 1. Methane Hydrate Structure I 512 cage (King, 2014) temperature are necessary.

Additionally as global temperature increase this will cause uncontrolled destabilization of methane hydrate. Methane is a strong greenhouse gas and uncontrolled release will further impact temperatures creating a self-feeding climate disaster. Understanding methane hydrate will become important as we try to avert this possible ecological disaster.

\subsection{Challenges Associated With Methane Hydrate Research}

As with most natural resources, the major considerations in accessing and using methane hydrate are the logistics and cost of field studies. Due to the complexity of laboratory-based experiments to test extraction methods for such a resource, computer based models have been developed to calculate expected outcomes from different extraction procedures. Once multiple models have been tested and an efficient extraction process has been identified, a cost analysis for the selected process can be performed. However, resource extraction models are based on the limited data obtained from well-bore analysis and laboratory experiments.

One parameter of great importance in model-building is a good understanding of the permeability of the hydrate-bearing sediment, and how the hydrate that occupies the pore space affects it (Jin, 2012). Since hydrates form and fill available pore space of a substrate, the permeability decreases as hydrate saturation increases. In order to study permeability and the effect hydrates have on it, Darcy's Law is used to correlate the changes. 


\subsection{Darcy's Law Applications to Microfluidics}

Darcy's Law is the empirical principle that governs how fluid moves though a porous media, and contains the equations that define the ability of a fluid to flow through porous media. Central to the Law is the fact that the amount of flow between two points is directly related to the difference in pressure between two points and the ability of the media to impede flow; this inverse factor of flow impedance is also known as permeability. Darcy's Law, shown in Equation 1, is a simple proportional relationship between the instantaneous mass flow rate through a porous medium and the decrease in pressure over a given distance (Darcy, 1856).

Darcy's Law equation:

$$
Q=\frac{k}{\mu} \frac{\Delta P}{L} A
$$

Where: $Q$ is the volumetric flow rate $\left(\mathrm{m}^{3} / \mathrm{s}\right)$

$k$ is the coefficient of permeability $\left(\mathrm{m}^{2}\right)$

$\mu$ is the dynamic viscosity (Pa-s)

$\Delta P$ is the pressure difference $(\mathrm{Pa})$

$L$ is the flow length (m)

$A$ is the cross sectional area of flow $\left(\mathrm{m}^{2}\right)$

If solved for permeability (the parameter of interest), two groupings of variables can be identified. For a given experimental step, the flow rate and pressure difference can be varied and measured while holding viscosity, length, and area constant (Equation 2).

$$
k=\frac{Q}{\Delta P} \frac{\mu L}{A}
$$

Using Equation 2, comparative experiments can be conducted to determine the permeability of a microfluidic chip with and without hydrate. Due to the complexity of a two phase mixture required to form methane hydrates, a single phase alternative is used. This alternative is a solution of tetrahydrofuran (THF) and water. Since THF is soluble in water, a single phase liquid can be used for flow testing and hydrate formation. Once baseline THF/water flow testing and high density hydrate flow testing is completed, analysis can be performed to compare the two. Using this framework, the permeability of the microfluidic chip without hydrate may be called the intrinsic permeability $\left(k_{\text {intrinsic }}\right)$, and the actual permeability $\left(k_{a c t}\right)$ is the permeability of the microfluidic chip containing hydrate. Thus, $k_{a c t}$ is a function of the hydrate saturation and may be measured and defined as:

$$
k_{\text {act }}=k_{\text {rel }} k_{\text {intrinsic }}
$$


The relative permeability $\left(k_{\text {rel }}\right)$ is the percent change in the intrinsic permeability $\left(k_{\text {intrinsic }}\right)$ due to the hydrate's effect on flow. Solving for relative permeability $\left(k_{\text {rel }}\right)$ :

$$
k_{\text {rel }}=\frac{k_{\text {act }}}{k_{\text {intrinsic }}}
$$

Using a microfluidic chip, the length $(L)$ and area $(A)$ of a given system would remain constant and therefore factor out. Both Q1 and Q2 will be conducted at the same temperature, resulting in constant viscosity $(\mu)$, which will also cancel out of the equation. Thus, relative permeability becomes a ratio of the volumetric flow of the actual permeability experiment and the volumetric flow of the intrinsic permeability experiment.

$$
k_{\text {rel }}=\frac{k_{\text {act }}}{k_{\text {intrinsic }}}=\frac{Q_{1} \mu L / \Delta P A}{Q_{2} \mu L / \Delta P A}=\frac{Q_{1}}{Q_{2}}
$$

\subsection{Permeability Models}

Since permeability quantifies the ability of a porous medium to conduct flow and is controlled by the geometry of the porous media, models have been developed to calculate permeability based on these geometries. As hydrate forms within a porous medium these geometries begin to change. Therefore relative permeability of hydrate bearing sediments depends on where and how hydrates form within the pore spaces. To calculate these effects, numerous models have been developed to explain the reduction of permeability in the presence of hydrates. The first and simplest model of consideration is the parallel capillary model, which relates the permeability to the porosity based on the pore geometry. This allows for the determination of relative permeability at a given hydrate saturation level $\left(S_{h}\right)$ by normalizing it with this model. The parallel capillary model is further divided into pore-coating and pore-filling models. Pore-coating models are based on the assumption that the hydrate uniformly coats the walls of the pore structure linking the media together; it is often referred to as cementing hydrate, equation 6 (Kleinberg et al., 2003).

$$
k_{r e l}=\left(1-S_{h}\right)^{2}
$$

Pore-filling models are based on the assumption that the hydrate forms with in the pore spaces acting as a plug within the pore structure, equation 7 (Kleinberg et al., 2003). However the parallel capillary model approximates the flow paths as straight cylindrical capillaries and the pore spaces are generally irregular and much longer that the capillaries that define the pressure gradient.

$$
k_{r e l}=1-S_{h}^{2}+\frac{2\left(1-S_{h}\right)^{2}}{\log \left(S_{h}\right)}
$$

The second model for consideration is the Kozeny models which assumes irregular pore spaces and flow paths. Kozeny models relate the permeability to porosity and grain size and again are classified into 
grain-coating or pore-filling. The Kozeny grain-coating model is defined by equation 8 (Kleinberg et al. 2003), where $n$ is the Archie saturation exponent. The Archie saturation exponent models the dependency on the presence of gas hydrates in the pore space, and is related to the wettability of the

$$
k_{\text {rel }}=\left(1-S_{h}\right)^{n+1}
$$

porous medium. The saturation exponent is usually defined $n$ as 1.5 for $0<S_{h}<0.8$ (Spangenberg, 2001) and for $S_{h}>0.8$ the saturation exponent diverges as any increase in the saturation exponent will have minimal impact on permeability. The Kozeny pore-filling model is defined in equation 9, below (Kleinberg et al., 2003).

$$
k_{r e l}=\frac{\left(1-S_{h}\right)^{n+2}}{\left(1+\sqrt{S_{h}}\right)^{2}}
$$

Spangenberg (2001) defines $n$ as equation 10.

$$
n=0.7 S_{h}+0.3
$$

Each of these models assumes uniform hydrate saturation and that either pore-filling or pore-coating exists. As we will see hydrate saturation is very heterogeneous and these assumptions will greatly affect relative permeability calculations when one permeability is assumed to be throughout the porous media, see Figure 11 for an example of this heterogeneity.

\subsection{Predictive Modeling of Methane Hydrate Resources}

Most laboratory experiments study hydrate saturation from 0 to 50\% (Kumar, 2010; Johnson, 2011). However, well-bore analyses show that natural hydrate formations often have a saturation of $50-85 \%$. Site HGHP-01-10 in Krishna-Godavari Basin, India, has drilling logs of gas hydrate saturations greater than $50 \%$ and as high as $80 \%$ (Lee, 2009). Mount Elbert Well, Alaska North Slope, has two identified hydrate zones with an average gas hydrate saturation of $50 \%$; both zones reach maximum hydrate saturations of $75 \%$ (Lee, 2011). Additionally (Ito, 2015) found that the hydrate saturation in the eastern Nankai Trough, Japan, surpassed 80\%. Figure 2 (taken from Dai, 2014) shows clustering of data below $50 \%$ hydrate saturation; the Kleinberg et al. data is from NMR extrapolations. Together, these findings highlight a gap in hydrate permeability data that correlates to saturation of known hydrate deposits. 


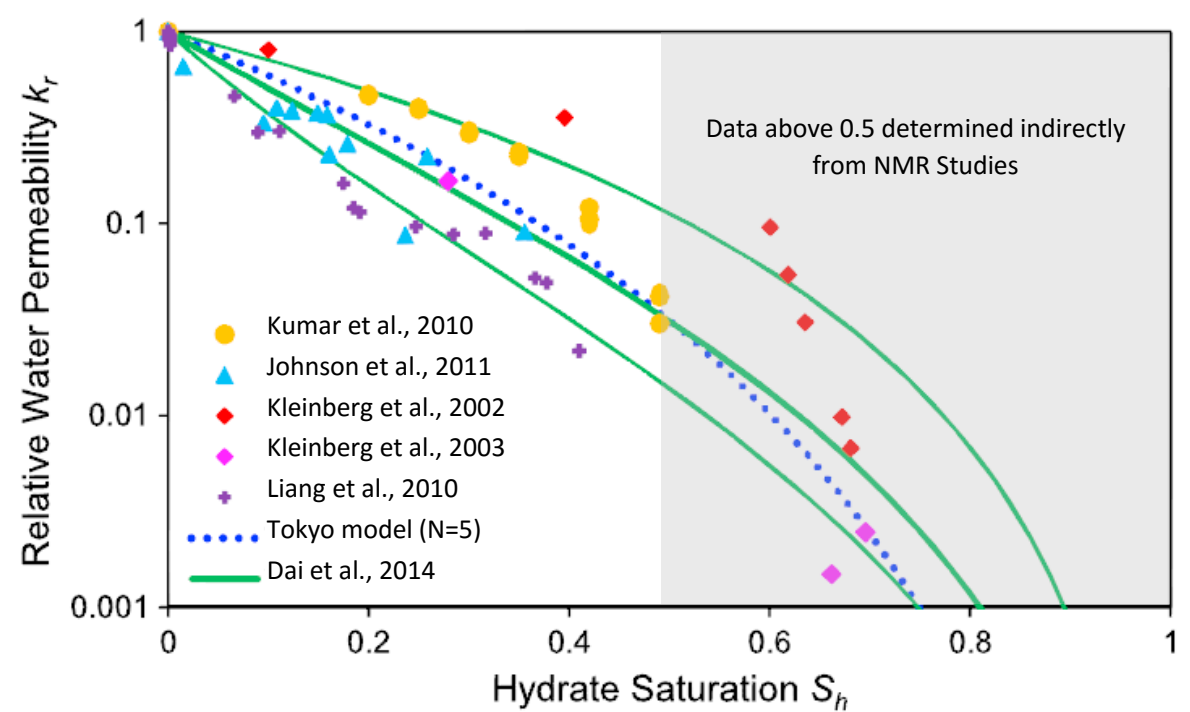

Figure 2. Comparison of models and experimental data of the relative water permeability as a function of hydrate saturation from (Dai, 2014)

Due to the inconsistencies between existing models and well-bore analyses, most computer models must extrapolate permeability of high saturation hydrate formations, adding further error to calculations. Sakamoto et al (2009, source of Figure 3), showed how gas production calculations change depending on the permeability curves used. As is illustrated, gas production predictions can vary widely based on what permeability curves are chosen. Since a gas hydrate well would be in production for 50 years, the resulting production values will vary greatly over time.

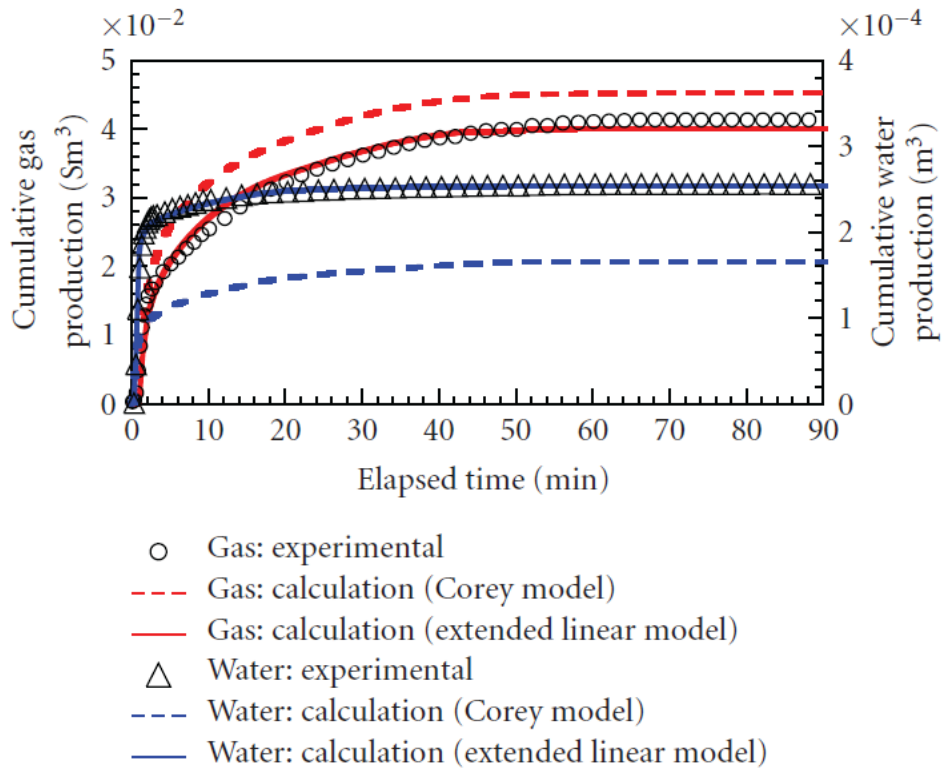

Figure 3. Comparison of experimental and calculated production when different relative permeability curves are used from (Sakamoto et al, 2009) 
Furthermore, as models increase in complexity, the need to understand how permeability changes as hydrate saturations move beyond current laboratory limits is vitally important. Liang et al (2010) found that existing permeability data of known substrates could be extrapolated via 3D mathematical modeling, thus reducing model error. Additionally, Delli et al (2013) established further computation correlations using statistical methods. These two examples still rely on the limited data from both laboratory and well bore experimentation to estimate the changes in permeability after hydrate saturations exceed $50 \%$.

\subsection{Review of Prior Hydrate Permeability Studies}

Given the limitations of natural hydrate studies and computational modeling, laboratory-based experimental systems capable of more accurately modeling hydrate permeability at high saturations and directly observed saturation distributions are needed. Though microfluidics has been predominantly used for biological and chemical analysis, emerging technology in 2D microfluidic models could be applied to the study of hydrate formation in porous media and the effects that hydrates have on permeability could be better characterized. Berejnov et al. (2008, source of Figure 4 and Figure 5) introduced a rapid prototyped microfluidic chip with a complex network of approximately 5000 channels to be used for the study of multiphase transport phenomena in porous media. The authors were able to show that mathematically-based porous media could be designed with a computer, created via etched Polydimethylsiloxane (PDMS) polymer (Figure 4a) and used to visualize wettability (Figure 4b).

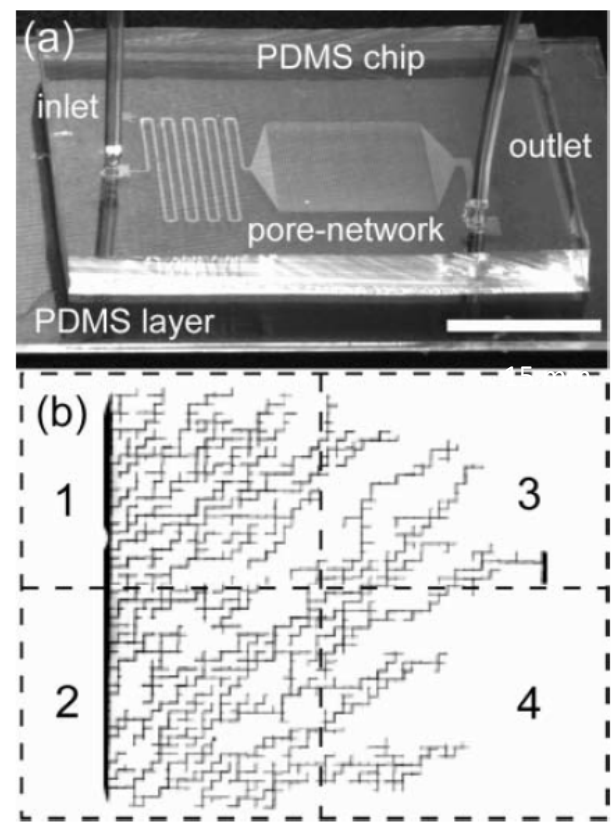

Figure 4. a) Microfluidic network chip, b) fluid permeation into the network from

(Berejnov et al, 2008)

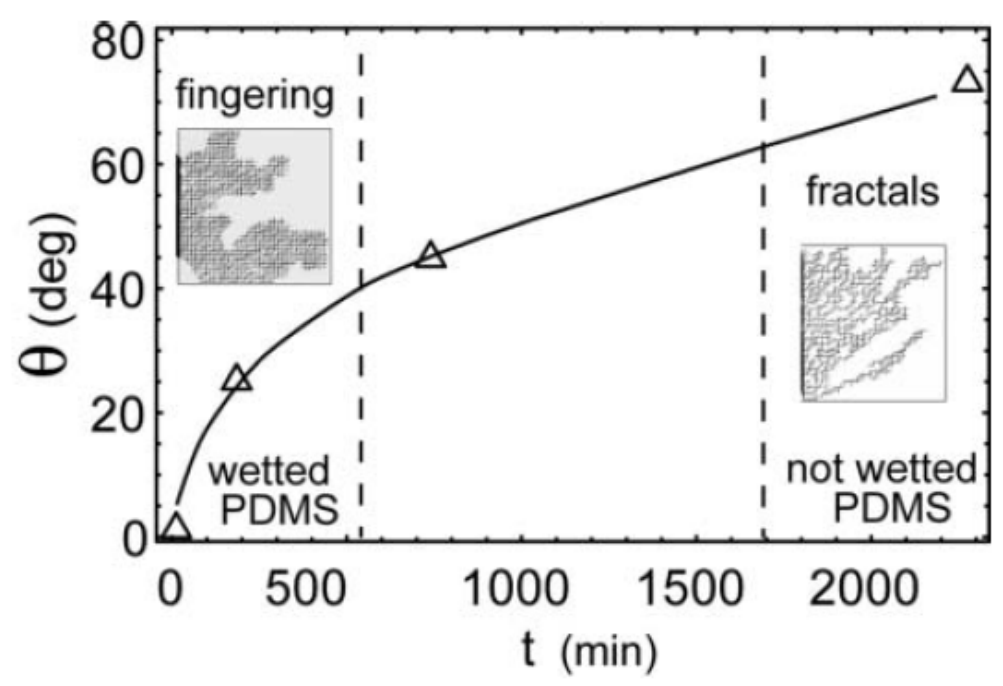

Figure 5. Wetting properties and corresponding network dynamics from (Berejnov et al, 2008)

These data showed that complex flow networks can be created, and that the surface properties could be modified to provide specific flow characteristics (Figure 5). Additionally, these multiphase transport conditions are particularly relevant to oil recovery, $\mathrm{CO}_{2}$ sequestration, and methane hydrate formation/permeability research. However, PDMS is not a suitable substrate for a microfluidic chip in a methane hydrate system because: 1 ) the low temperatures needed for hydrate nucleation can cause it 
to become brittle; and 2) the high pressures needed for hydrate stability could cause it to fracture. The best alternative to PDMS is silicon glass, because of its strength and temperature tolerance; additionally, the optical clarity of silicon glass could be useful for visualization of hydrate formation.

To further enhance the pore network to better mimic natural rock, Bera et al (2011) used focused ion beam-scanning electron microscopy (FIB-SEM) to image a rock core sample and convert that to a 2D network that could be etched onto a glass substrate. The authors started with a core sample, taken from a specific reservoir, so that its pore structure could be analyzed via FIB-SEM, which provided a 3D rendering of the reservoir's pore structure. These images were processed via a computer to obtain a realistic 2D pore network cross-section that was etched on silicon glass. This process significantly increased the likelihood that laboratory-produced flow data would mimic that of the natural rock within the reservoir. Being that methane hydrate reservoirs vary in composition, this method allows for greater accuracy between the laboratory and real-world models. Figure 6 (taken from Bera et al, 2011) details this process.

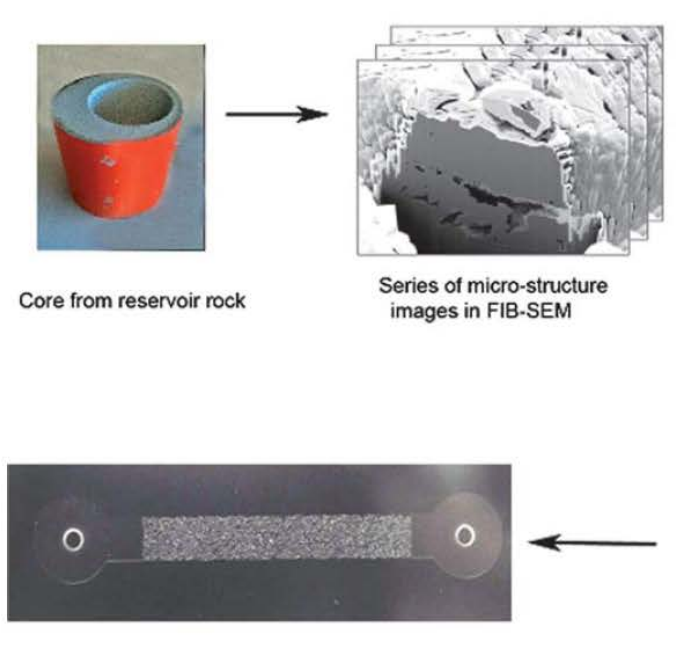

Reservoir-on-a-Chip (ROC)
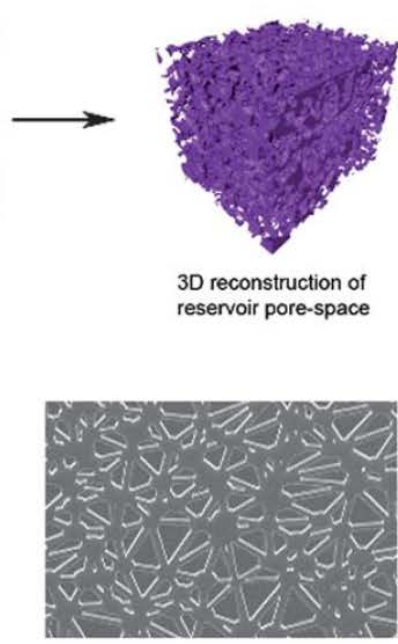

Etched network in silicon

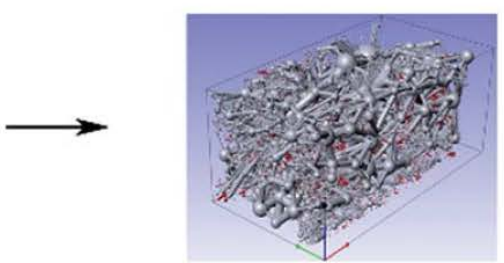

Pore-network extracted from 3D reconstruction

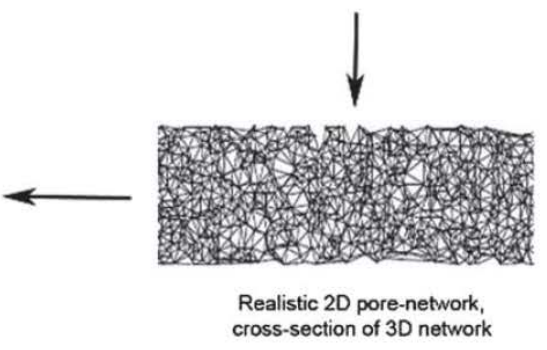

Figure 6. Conceptual map of the process to produce a "Reservoir-on-a-Chip" from (Bera et al, 2013)

Additionally, Joseph et al (2013) showed how the above designed "Reservoir-on-a-Chip" could be used to study porosity and permeability. The authors began with a Delaunay Triangulation routine performed with MATLAB (MathWorks Inc., Natick, MA, USA) to design a pore network based on a typical sandstone microstructure. The authors then modified the pore network by changing the number of pores and throats present to verify that the created substrate would emulate known permeability in sandstone. Four iterations of this computer-generated pore network were manufactured in silicon glass (Figure 7 and Figure 8, taken from Joseph et al, 2013). Each of these microfluidic chips was then tested to determine porosity and permeability. Figure 8 shows that as the number of pores and throats increases so does permeability. Therefore network 1 has the lowest permeability of $2.66 \pm 0.06$ Darcy, network 2 is $5.50 \pm 0.40$ Darcy, network 3 is $10.88 \pm 1.03$ Darcy, and network 4 has the highest permeability of $15.93 \pm 0.55$ Darcy. This illustrates the importance the geometry of the pore structure has on permeability. 


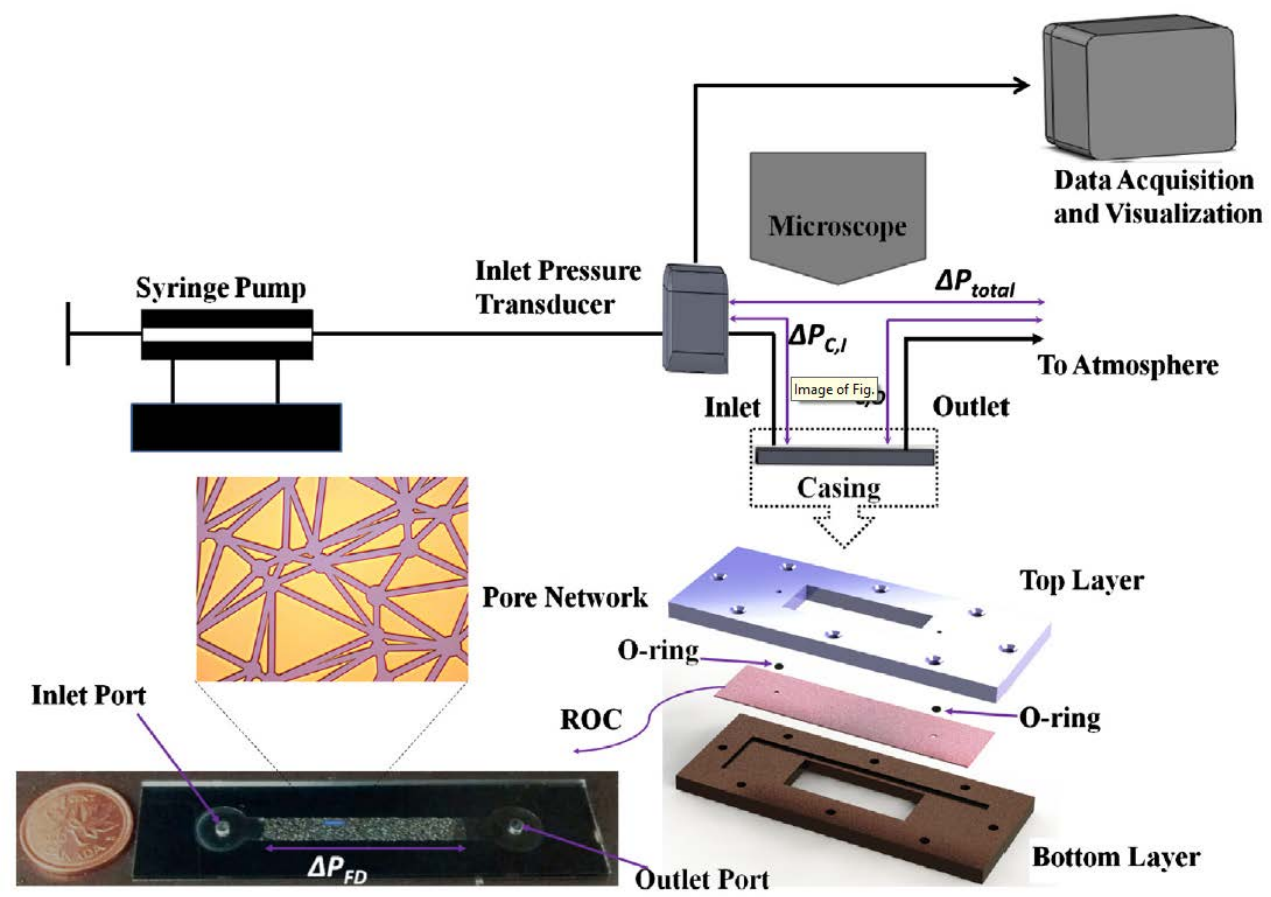

Figure 7. Schematic of the experimental set-up for porosity and permeability measurements from (Joseph et al, 2013)

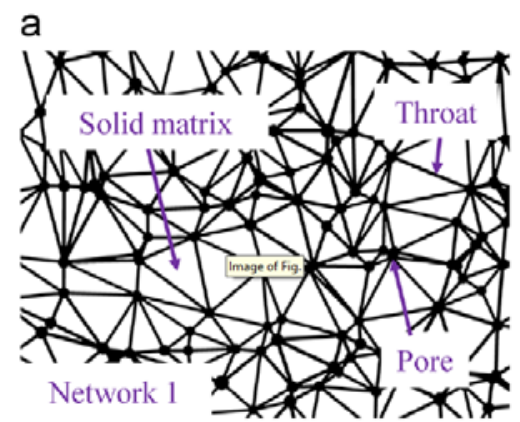

b
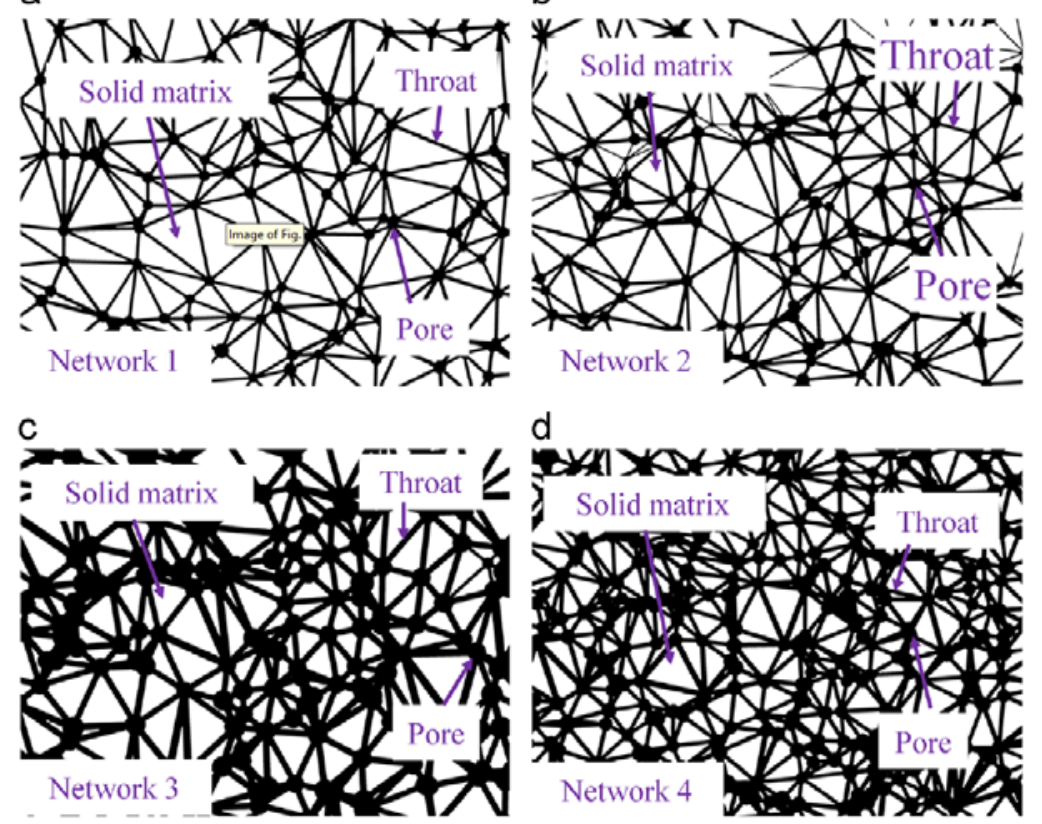

d

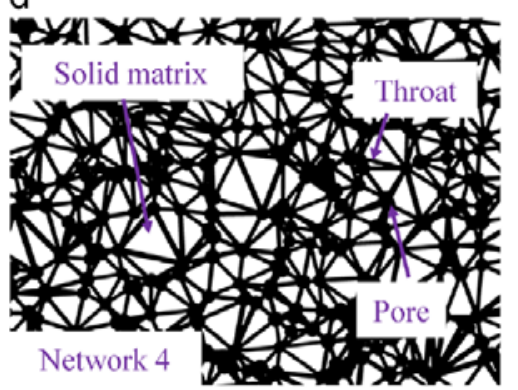

Figure 8. a) network 1 contains 2000 pores and 6000 throats, b) network 2 contains 3000 pores and 9000 throats, c) network 3 contains 3000 pores and 9000 throats with larger throat volume, and d) network 46000 pores and 20000 throats from (Joseph et al, 2013) 
Taken together, these experimental findings demonstrate that microfluidics provide a key analytical tool for emulating the pore structure of natural rock. Thus, with a specific parent rock selected from a reservoir of interest, a microfluidic chip can be designed and constructed from a material that can withstand the pressures and temperatures needed for the study of methane hydrate (ie, silicon glass). With these new microfluidic chips, more accurate assessment of permeability will be possible when combined with the increased hydrate saturations that mimic natural hydrate reservoirs.

The first use of microfluidics in the study of hydrates is attributed to Tohidi et al (2001); in this paper, the authors constructed a glass micromodel for use in the visualization of hydrate formation. Though the micromodel consisted of a regular pattern etched into silicon glass, which did not mimic a real pore network, initial results were promising. The authors were able to demonstrate growth of $\mathrm{THF}, \mathrm{CO}_{2}$, and methane hydrates across the microfluidic chip (Figure 9, taken from Tohidi et al, 2001). These experiments demonstrated the key idea that laboratory-formed hydrates were no longer confined to large 3D matrices requiring expensive imagine techniques for visualization; rather, they could be imaged directly within the pore structure of the microfluidics model.

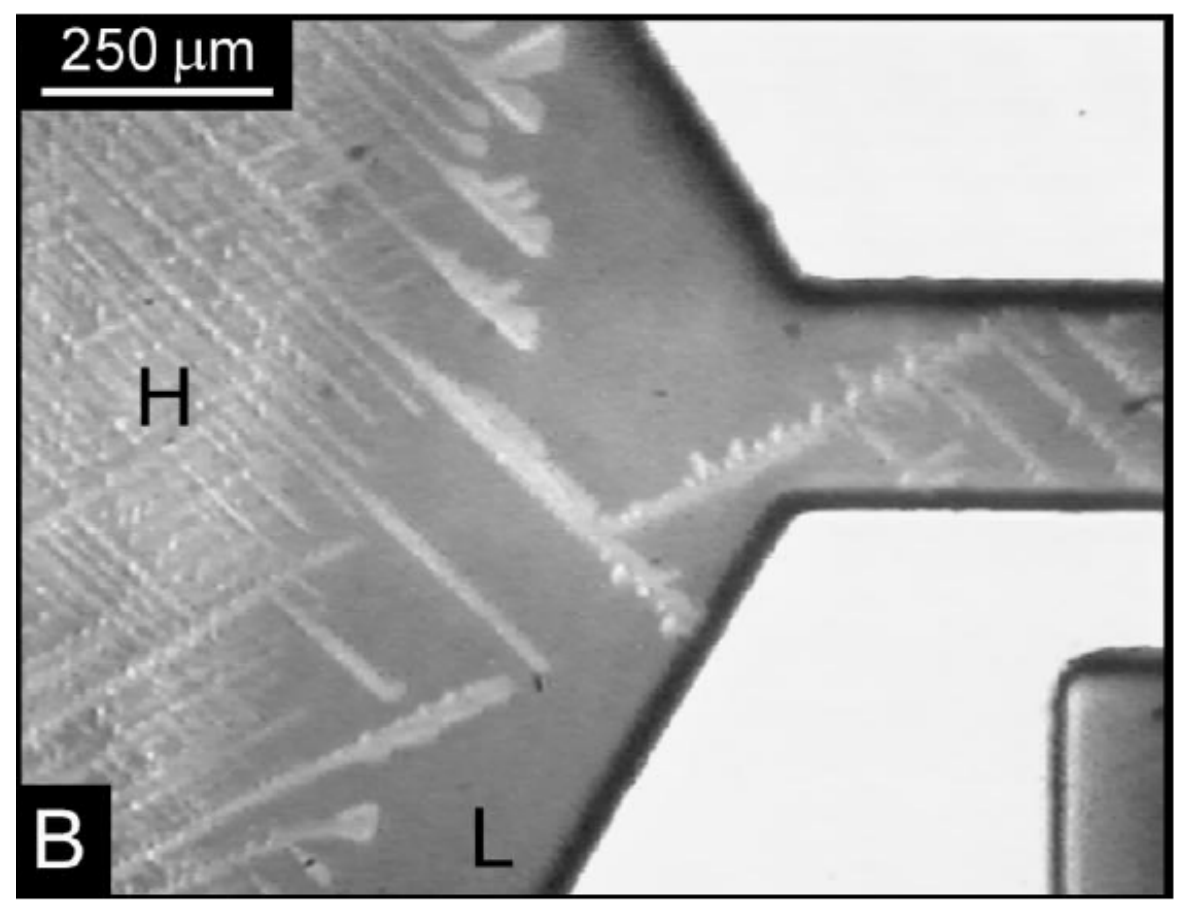

Figure 9. Hydrate formation (H) and dyed liquid (L) from (Tohidi et al, 2001)

In a related study, Ohmura et al (2008) studied the dissociation of methane hydrate crystals in a glass micromodel. Here again, a simplified microfluidic pore network was created by etching a glass plate to produce a grid pattern. The authors were able to show (Figure 10, taken from Ohmura et al, 2008) the complex composition resulting in methane hydrate dissociation. 


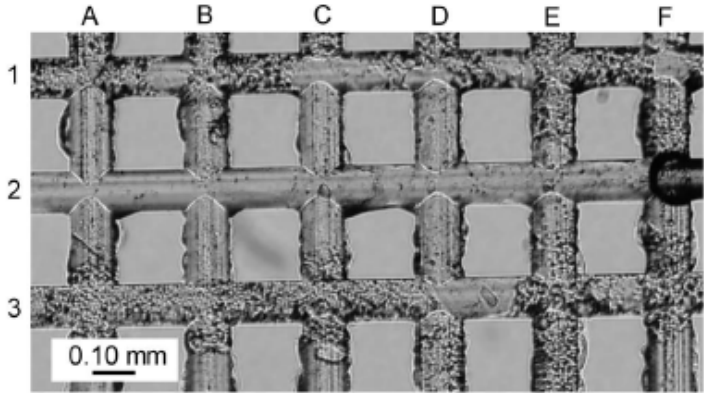

(a) $29.67 \mathrm{~min}$

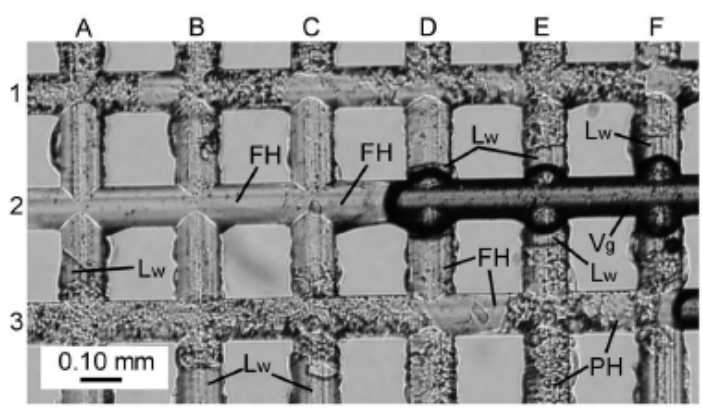

(c) $38.92 \mathrm{~min}$

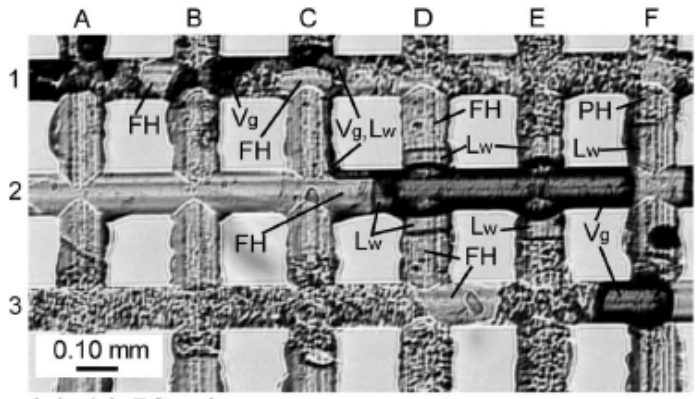

(e) $41.50 \mathrm{~min}$

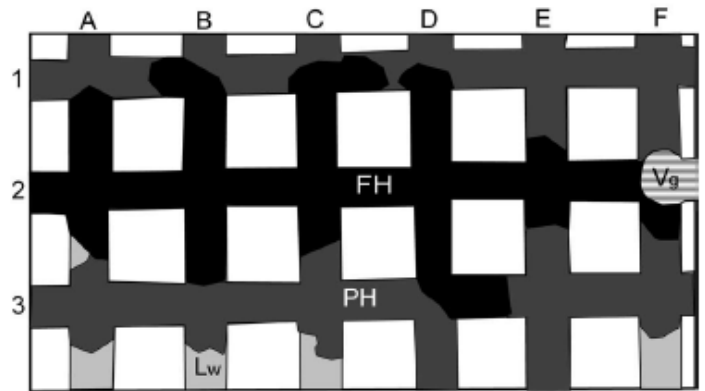

(b) $29.67 \mathrm{~min}$

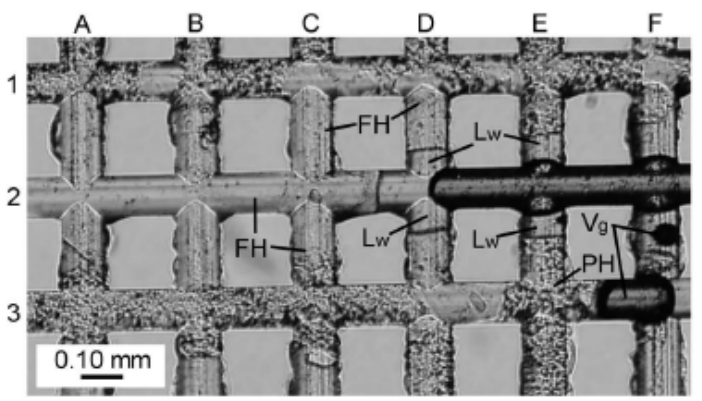

(d) $41.47 \mathrm{~min}$

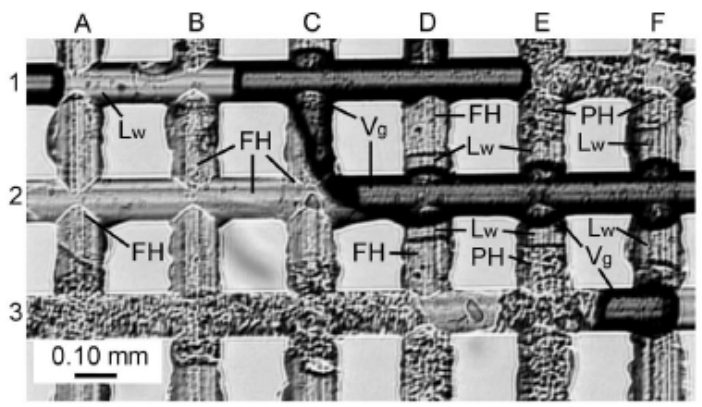

(f) $41.83 \mathrm{~min}$

Figure 10. Time lapse images of dissociation of methane hydrate. (PH) particulate hydrate crystals, (FH) faceted hydrate crystals, $\left(L_{w}\right)$ liquid water, and $\left(V_{g}\right)$ gaseous methane from (Ohmura et al, 2008)

As demonstrated in the above studies, visualization of a model system is equally important to its creation. The ability to adequately observe dissociation in accurate experimental models will be key to understanding how to better extract and exploit natural methane hydrate reservoirs. Thus, the use of an optical microscope enables real-time visualization of hydrate formation and dissociation - a feature that other traditional imaging techniques (eg, computed tomography, CT) do not provide. This important point is highlighted in a study by Feng et al (2009), which used CT images of THF hydrate formed around glass beads in a polypropylene cell, but only after hydrate was formed. Real-time processes were not monitored. Another example is provided in a study by Ryan (2012), which showed the formation of methane hydrate around different sediment compositions (Figure 11, taken from Ryan, 2012), but only after the hydrates were formed. This is a perfect example of the heterogeneity of hydrates within the porous media. This heterogeneity greatly influences permeability and as previously discussed the assumption of a single permeability throughout the porous media will drastically vary the computed permeability used in numerical models. 


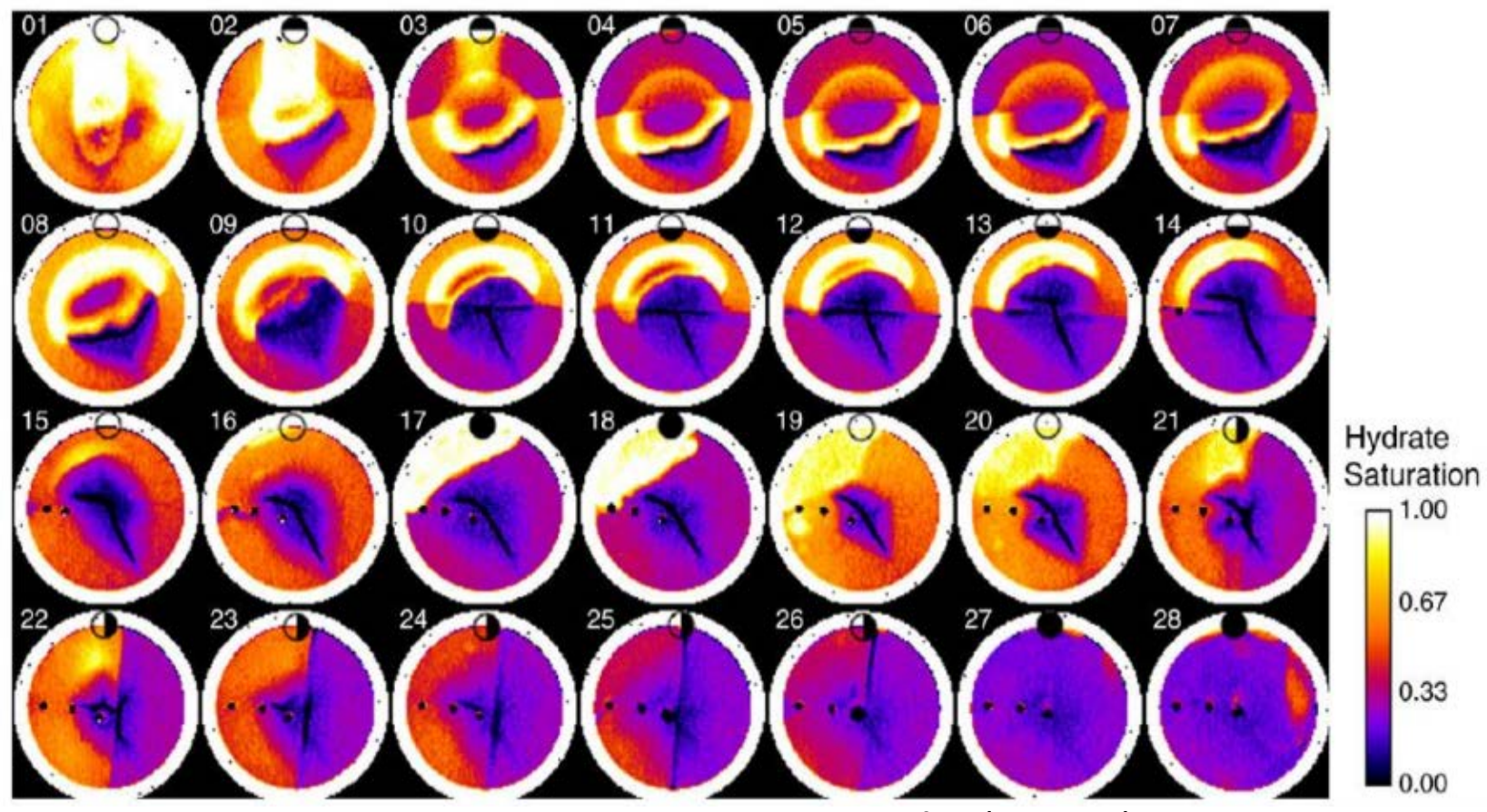

Figure 11. CT images showing hydrate saturation from (Ryan, 2012)

In addition to $\mathrm{CT}$ imaging, hydrate formation and morphology can be visualized using Raman spectroscopy (Linga et al, 2009) and/or attenuated total reflection infrared spectroscopy (Jin et al, 2012).

To advance this area of research, Kneafsey et al (2011) used CT imaging to first confirm hydrate saturation levels in their model, and then performed permeability studies. The data were then correlated with existing mathematical models; however, instrumentation limited their ability to determine changes in permeability when saturation exceeded 50\%. Similarly, Liang et al (2011) measured permeability with methane gas flow and correlated with theory predictive models; however, the methane hydrate saturation calculations were based on initial water saturation levels instead of direct measurements. Adding to these studies, Kumar et al (2010) used a Jerguson flat glass gage-cell filled with glass beads (Figure 12, taken from Kumar et al, 2010) to view their system, but hydrate saturation was again calculated based on initial water saturations and not experimentally determined. In summary, all of these experiments were conducted using large cells that use either glass beads or composited sands to form a porous media, requiring expensive and lengthy imaging, and reducing the ability to view the system in real time. 


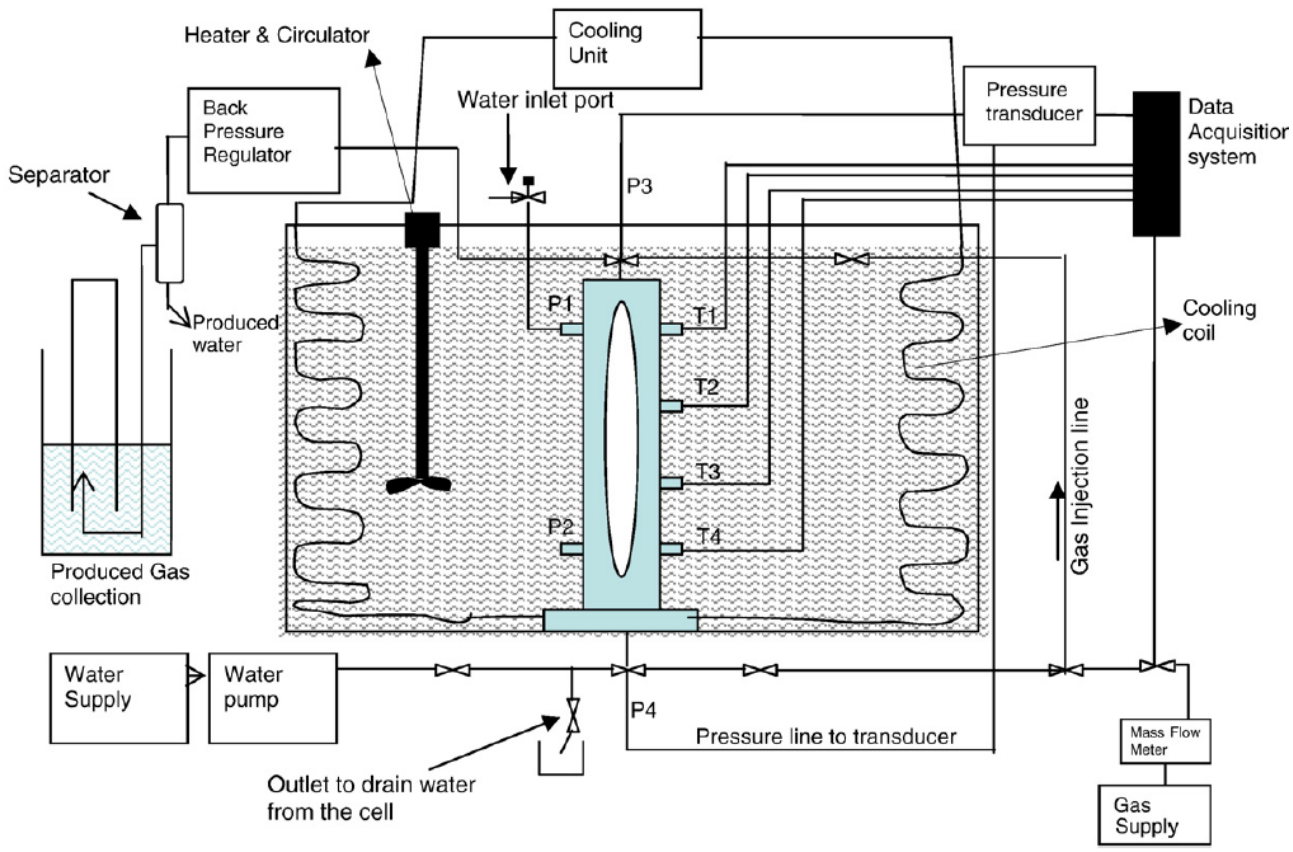

Figure 12. Schematic for experimental apparatus from (Kumar et al, 2010)

Reviewing these studies sequentially, it is clear that models of methane hydrate formation, dissociation, and permeability exist but still require improvement. Of all of these experiments, none truly combined microfluidics with optical visualization to confirm hydrate saturation and then determine permeability; a merger of saturation studies, permeability determinations, and hydrate visualization under high saturation conditions methane hydrate concentrations is still needed.

With the understanding that 2D modeling of porous media containing high saturation hydrate has not been studied before, the purpose of this research is to fill the data gap by designing and building a system for the study of permeability of a porous media with hydrate saturations above $50 \%$. This research is designed to provide further insight into the conditions in which methane hydrate can be extracted from soil reservoirs, and will be accomplished using a 2D microfluidic modeled porous media (inspired by the apparatus shown in Figure 7). Within this model, hydrate will be formed within the pore structure, analysis of flow will be conducted, and this model will be designed for real-time visualization using an optical microscope. 


\section{Objective}

The objective of this research is to design, build, and implement a system that uses a commercially available microfluidic chip that mimics a porous media for use in studying the effects of hydrate formation on permeability. The system must provide stable temperature control from $-20^{\circ} \mathrm{C}$ to $10^{\circ} \mathrm{C}$ and stable pressure gradients across the chip at pressure from atmospheric to $1250 \mathrm{psi}$. Imaging will need to provide adequate zoom from full chip width to the pore level with maximum resolution for post processing of images. The system will also need to control temperature gradient across the face of the chip to aid in the formation of methane/ water hydrates. 


\section{System Design}

A commercially-available porous media microfluidic chip available from Dolomite Microfluidics (Part\# 3200284) will serve as the substrate (Dolomite, 2015). The two main reasons a microfluidic chip is used in these experiments are: 1 ) to reduce variability in hydrate formation; and 2) ease visualization of hydrate formed. Reduced variability comes from the simplified two dimensional architecture of the chip relates to the more complex three dimensional real world. Second, visualization of laboratory scale experiments is often performed using CT scanning which limited resolution and make real-time analysis impossible. CT scanning requires expensive machines and the use of $x$-ray invisible materials. The microfluidic chip, Figure 13, shows the porous zone to be $10 \mathrm{~mm}$ by $60 \mathrm{~mm}$ (Figure 13A). The $10 \mathrm{~mm}$ cross section is then further divided into 5 sections each $2 \mathrm{~mm}$ by $2 \mathrm{~mm}$ (Figure 13B). Within this $4 \mathrm{~mm}^{2}$ section a random pattern of constrictions, $85 \mu \mathrm{m}$ and $63 \mu \mathrm{m}$, on the $110 \mu \mathrm{m}$ wide channels form the bases of the porous media zone Figure 13C, D). This $4 \mathrm{~mm}^{2}$ layout is then repeated across the remaining surface of the microfluidic chip.

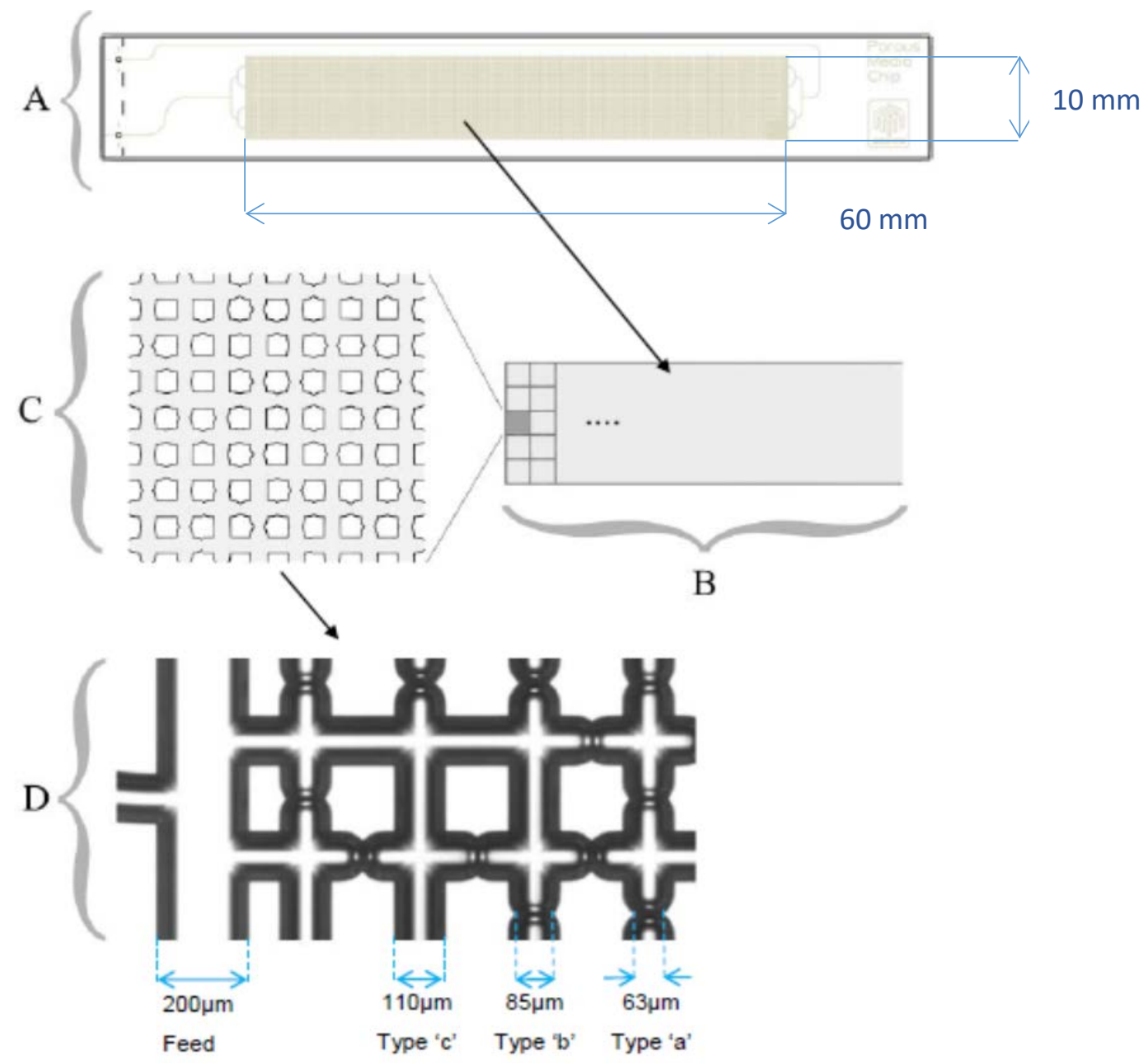

Figure 13. Dolomite microfluidic chip design details from (Dolomite, 2015) 
The bore restrictions (detailed in Figure 13D) are used to imitate the natural variability of pore and channel size. The microfluidic chips manifold is attached to one end of the chip, providing a mounting point for inlet and outlet ports. The manifold accepts standard 1/16-inch Polyether ether ketone (PEEK) tubing compression fittings. This configuration allows the system to have a working pressure of 100 bar. Figure 14, shows the microchip and manifold assembled and the plumbing of the inlet and outlet ports.

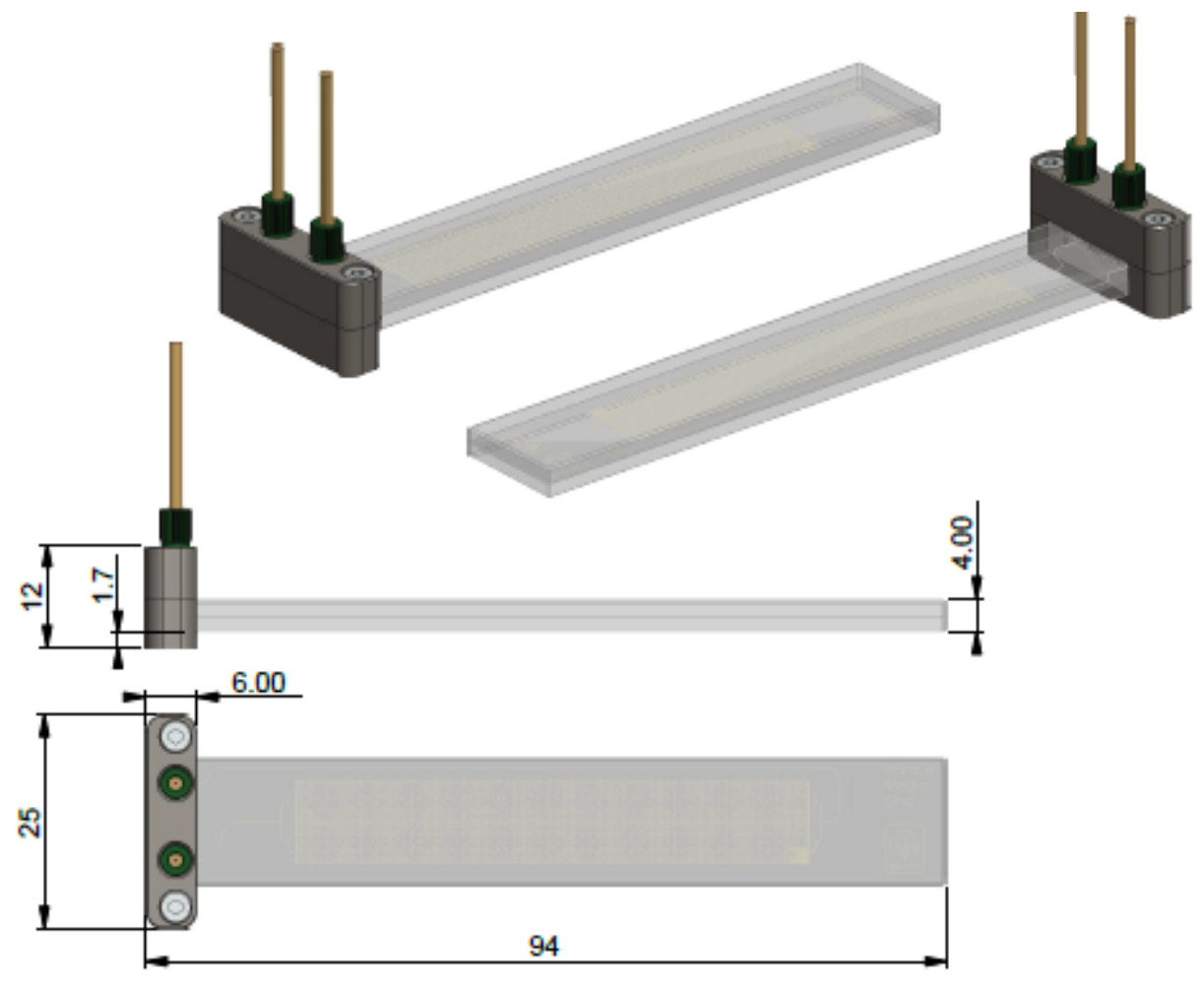

Figure 14. Chip with Manifold Mounted [mm]

The cooling system consists of two thermoelectric cooling (TEC) plates controlled by proportionalintegral-derivative controller (PID) type controllers. The TEC plates are spanned by a $3 \mathrm{~mm}$ thick $76 \times 300$ $\mathrm{mm}$ copper plate. The microfluidic chip is centered on the copper plate but is not in direct contact with either TEC plate. This allows for the formation of a temperature gradient across the chip. The temperature gradient can also be moved via the positioning of the TEC plates under the copper plate, which is controlled via a linear slide. Control of the temperature gradient gives better control over the position where hydrate will form within the chip.

The TEC plates operate on 12-volt direct current (DC) power supplies and are switched via solid state relays (SSR), which are in turn controlled by PID type controllers. Figure 15 shows the wiring schematic, which consists of a 12 volt power supply providing power to two circuits. The first circuit powers the PID temperature controllers and the second circuit powers the Peltier plates. These two circuits are connected via the Solid State Relays, which provide the link between the controllers and peltier plates. 


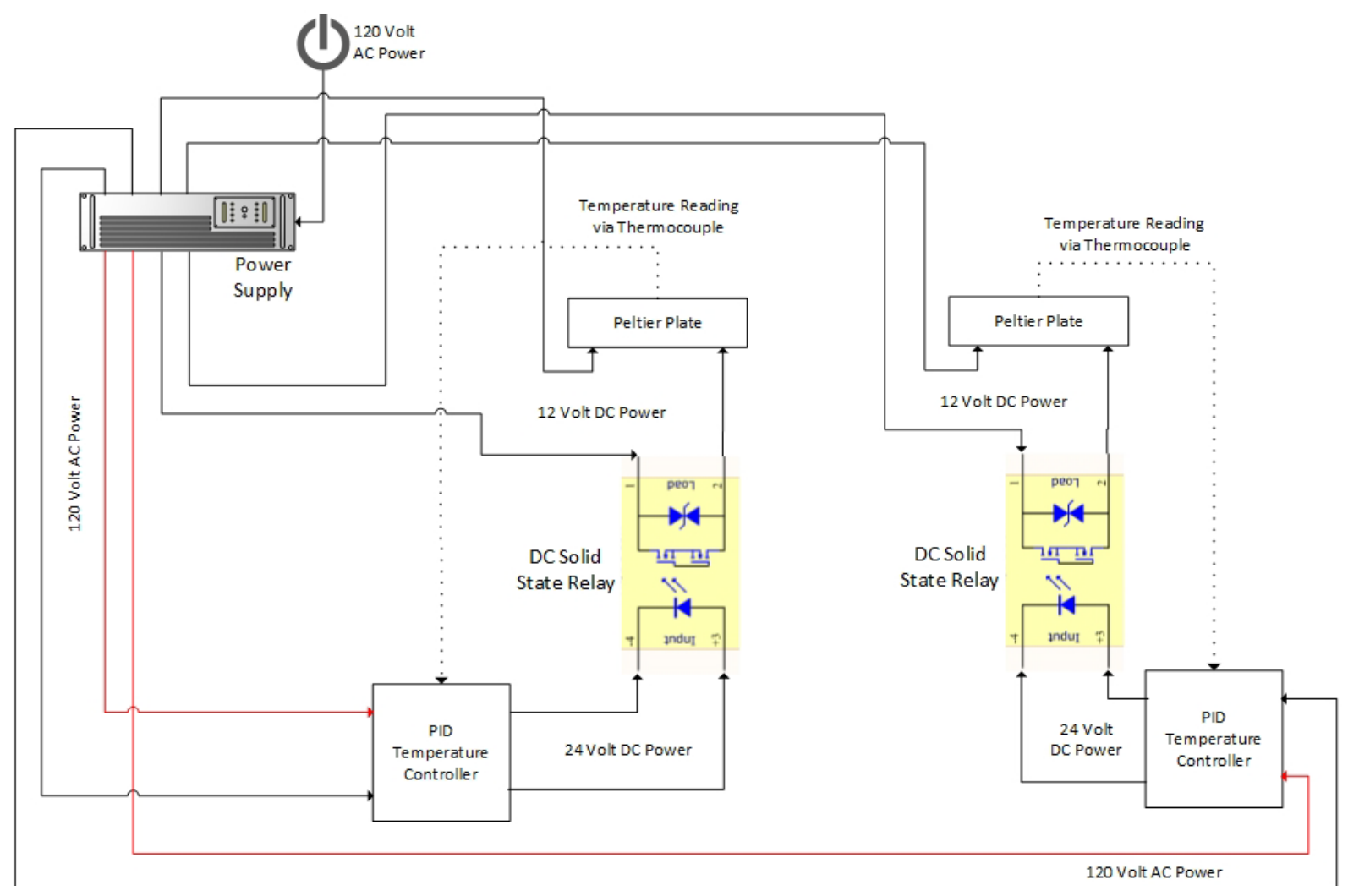

Figure 15. Wiring Schematic

Due to the excess of heat generated on the "hot" side of the TEC plate, a water/glycol cooled mount is used to remove unwanted heat. Figure 16 shows the flow of the cooled water/glycol solutions as it flows from the chiller bath into the Peltier plate mounts and SSR mounts, flow is in series. The SSRs are cooled to improve longevity.

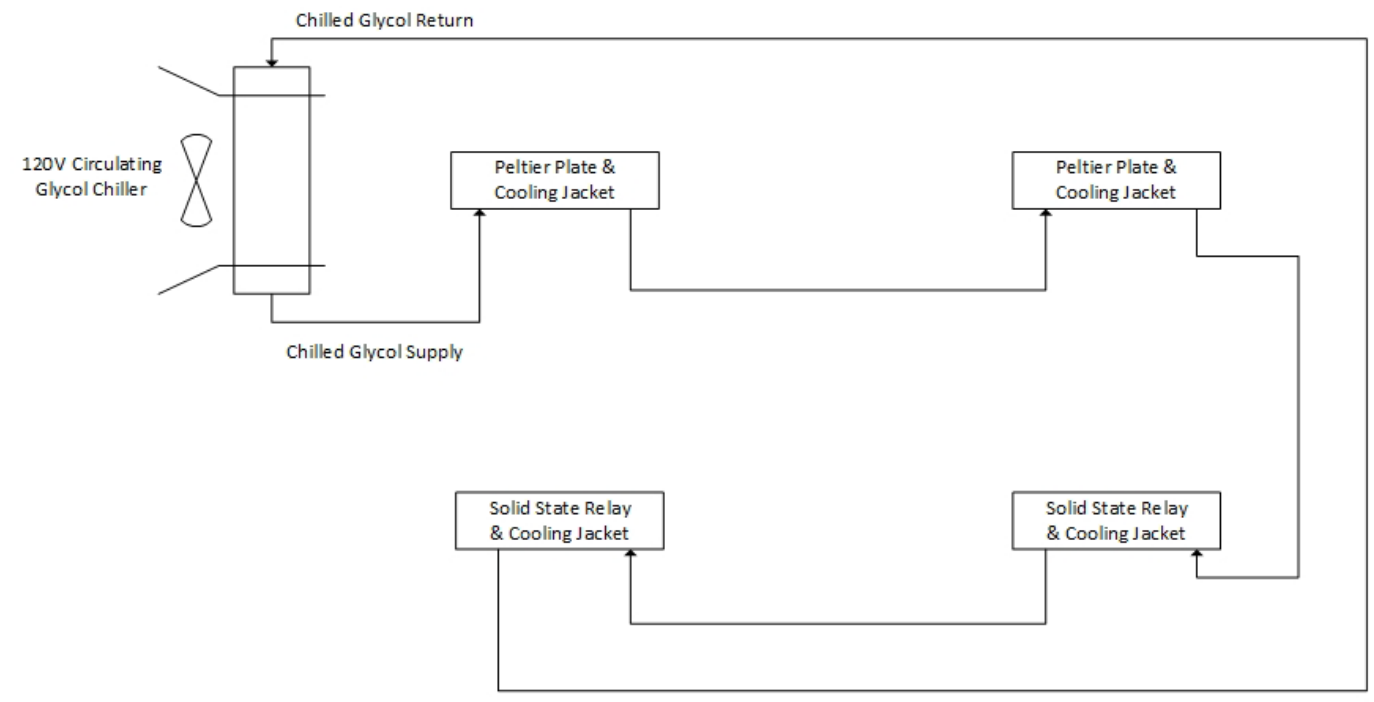

Figure 16. Peltier Plate Cooling System Diagram 
For the flow control system, a $150 \mathrm{~mL}$ reservoir is filled with a liquid tetrahydrofuran (THF)/water mixture and pressurized using compressed air (Figure 17). The pressure is controlled via a pressure regulator and monitored using a pressure transducer. Pressure adjustment will allow for establishment of a pressure gradient across the chip, thus creating a flow field. Effluent is collected and weighed over a given time, allowing for calculation of mass flow rate (grams of effluent/time in minutes). This mass flow rate is applied in Darcy flow equations to derive the permeability.

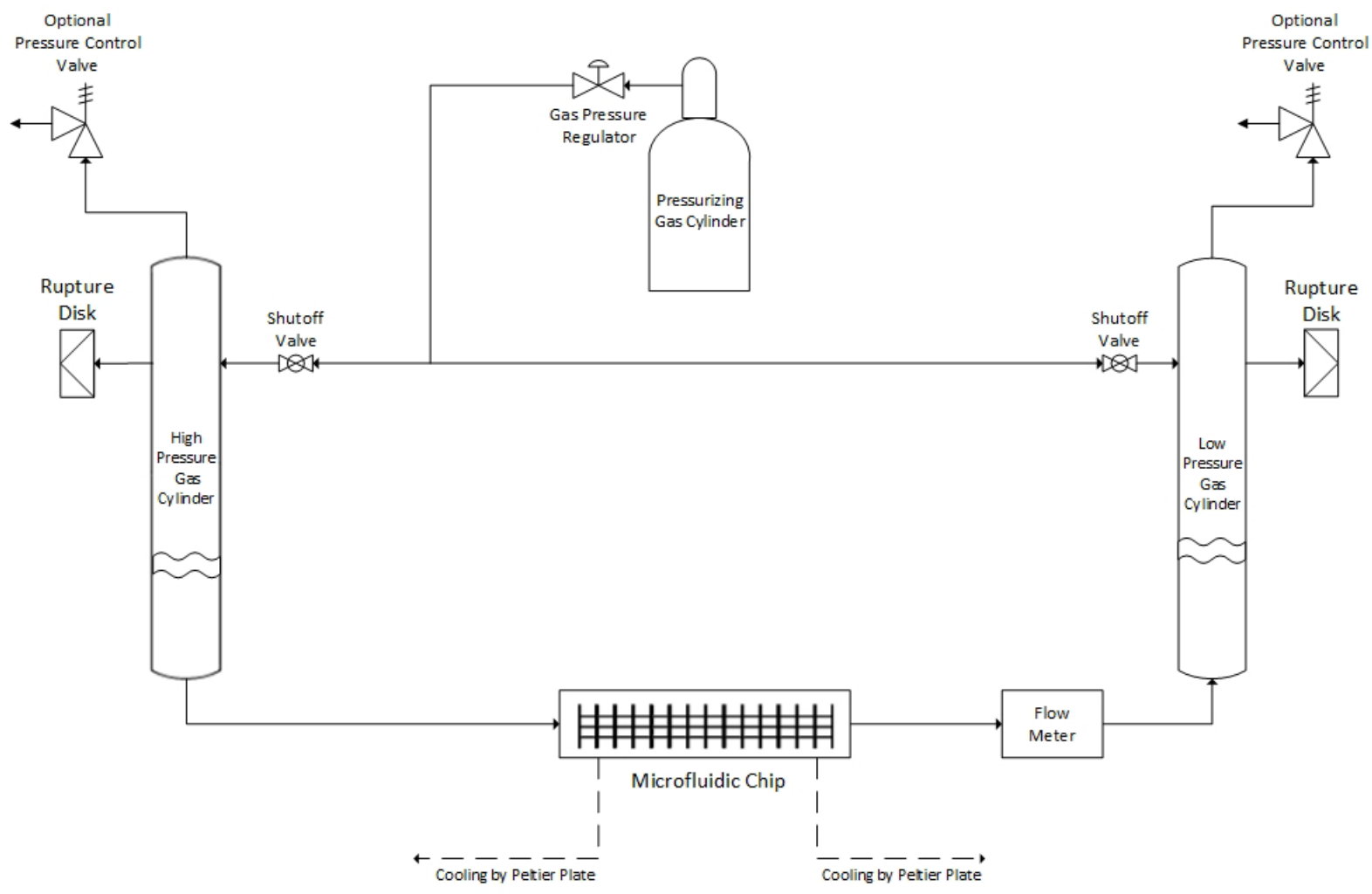

Figure 17. Fluidics for Flow Modeling

For image capture, a ZEISS Stemi-2000 microscope (Zeiss, Germany) is used with a x0.4 lens to view the entire $10 \mathrm{~mm}$ width of the chip. The $60 \mathrm{~mm}$ length of the chip is scanned by moving the XY stage upon which the chip apparatus is mounted. Video is captured using an Infinity X-32 Microscope Camera (Lumenera Corp., Ottawa, Ontario, Canada) camera mounted axially via c-mount on the microscope. The images/videos are processed using ImageJ (National Institute of Health, Bethesda, Maryland, USA) to determine hydrate saturation. 


\section{System Testing}

Initial system design filled the need to control the temperature across the length of the microfluidic chip while providing clear visualization with the microscope. As the system was utilized it evolved into the current design pictured in the images below. Figure 18 is an overall view of the system with all components shown. From the upper right hand corner clockwise, the computer is used to log the temperature profile across the microfluidic chip and record still images of the microfluidic chip so that hydrate saturation can be calculated. The PID controllers use a temperature feedback loop to maintain set temperatures of the Peltier plate in conjunction with the SSR's. The microfluidic chip is contained within the cylindrical humidity control chamber below the microscope and below that are the Peltier plates and cooling mounts housed in insulation. The chiller bath on the far left is used to circulate chilled glycol/water solution throughout the system to keep the Peltier plates and SSR's from overheating. Behind the microscope which is used to magnify the microfluidic chip, the pressure gauge allows for precise control over the reservoir used to create the flow across the microfluidic chip.

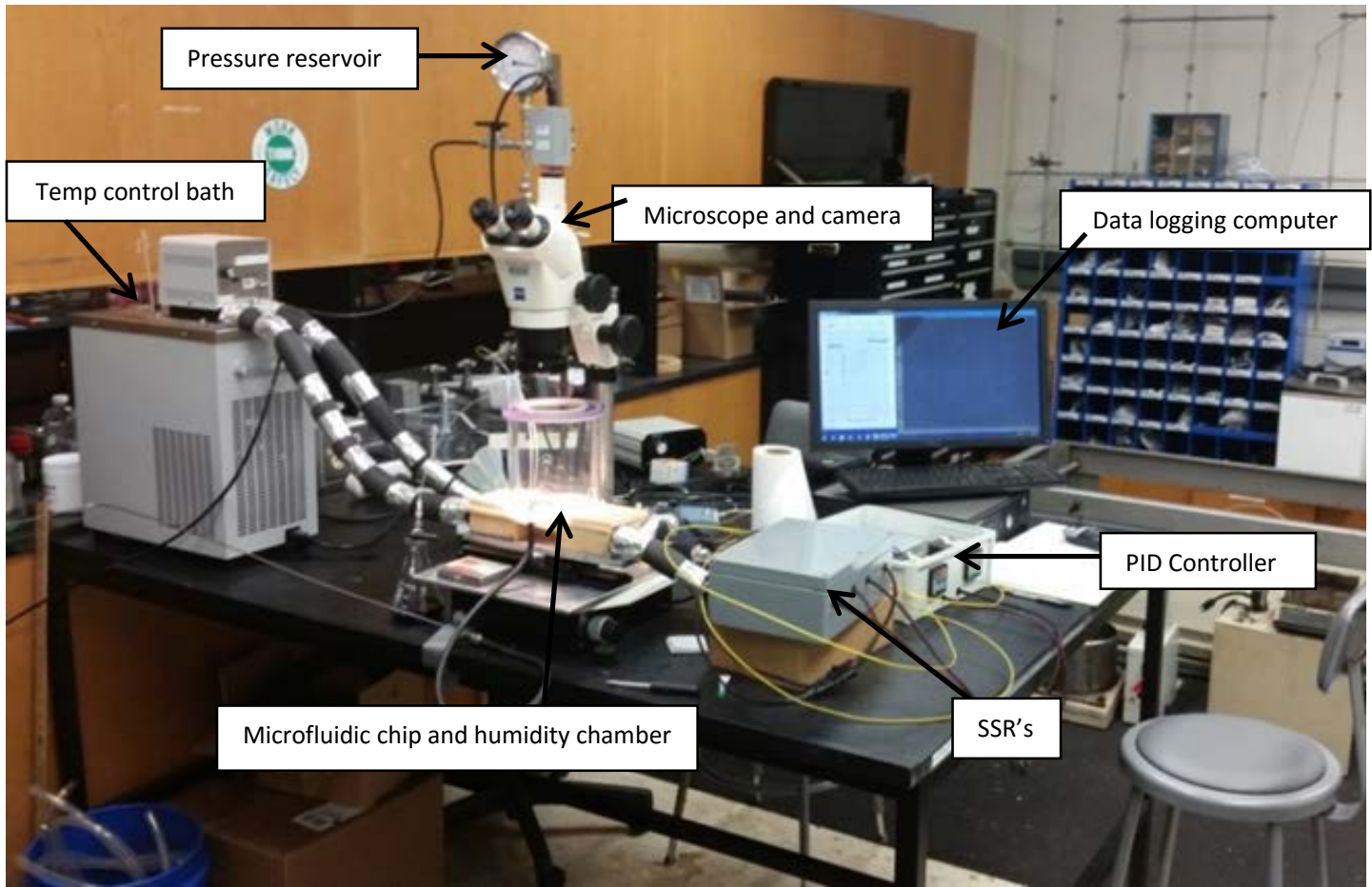

Figure 18. Complete system containing (from left to right) the temperature control bath, microscope, microfluidic chip, humidity control chamber, solid state relays, PID controllers, and data logging computer.

The Infinity X-32 camera at the top center of Figure 19, below, is connected to a Zeiss Stemi-2000 microscope with a fiber optic light ring illuminating the microfluidic chip inside the humidity control chamber that is mounted to the Peltier plates and cooling mounts. Insulation is used to reduce condensation on the exterior and aid in temperature control. The $150 \mathrm{~mL}$ reservoir, Figure 20 below, contains the THF/Water solution that is injected into the microfluidic chip. Using regulated compressed air the pressure can be controlled to vary the pressure gradient across the microfluidic chip. 


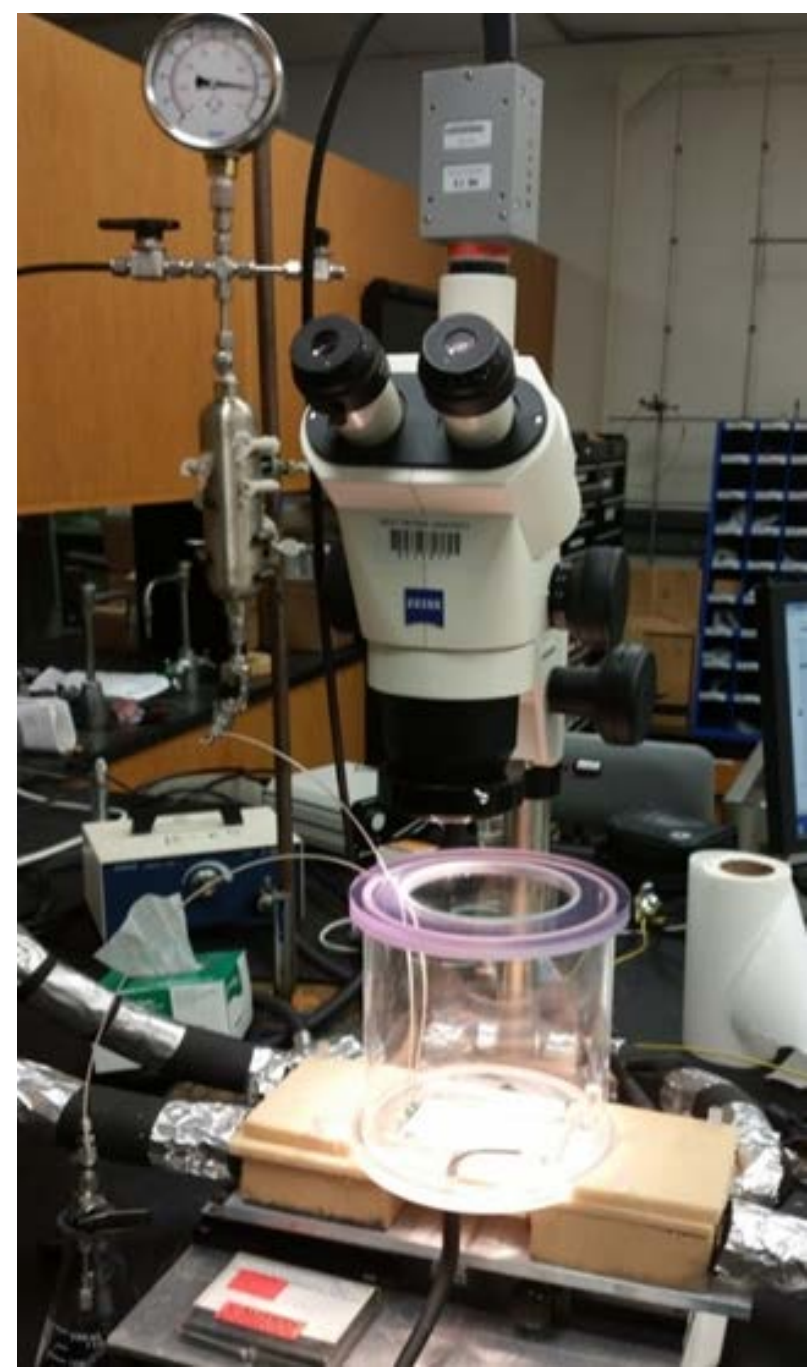

Figure 19. Ziess Stemi-2000 microscope and Infinity X-32 camera imaging the chip through the humidity control chamber.

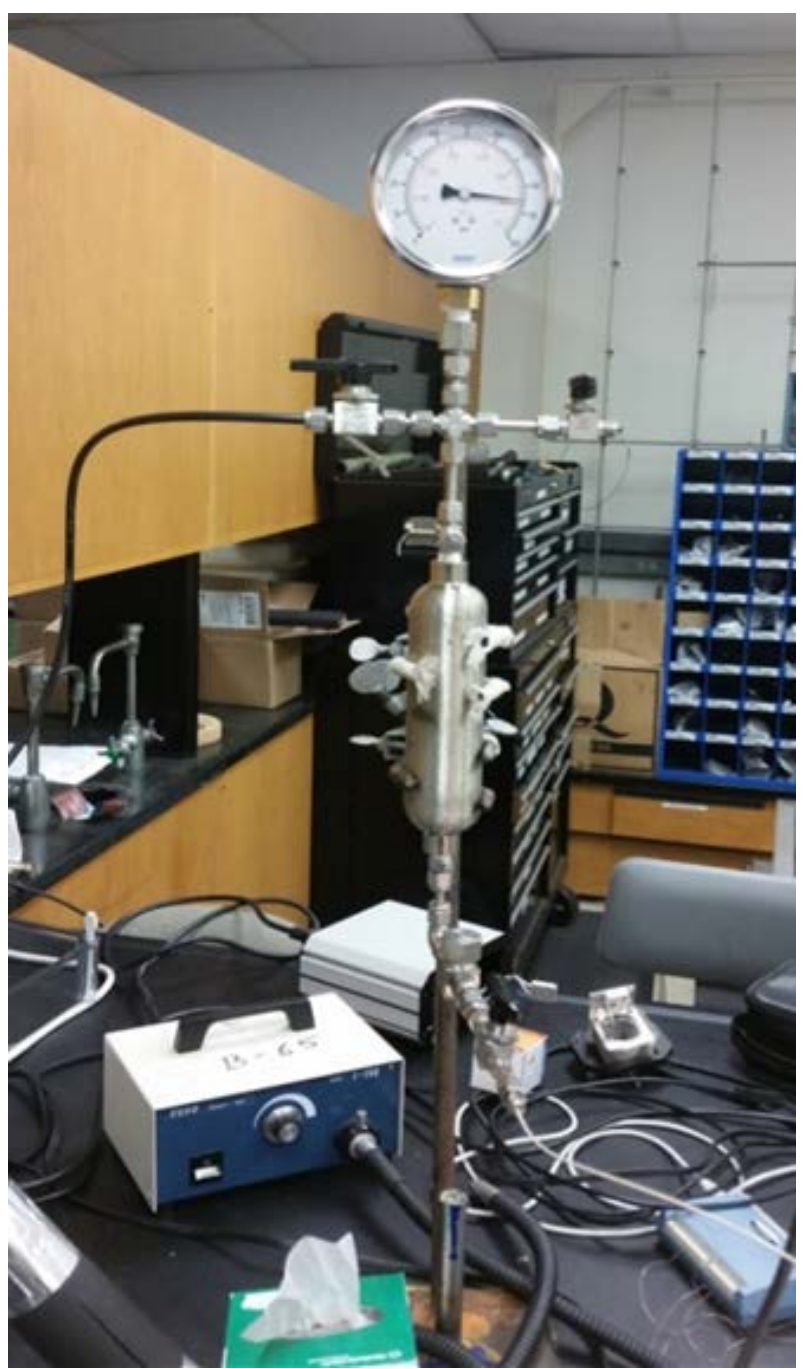

Figure 20. Pressurized reservoir and control valves

Figure 21, below, provides a close up view of the microfluidic chip, flooded with dyed THF/Water solution, contained within the humidity control chamber. The polycarbonate chamber allows for dry air to be circulated across the microfluidic chip to reduce condensation that hinders visualization with the camera. An aluminum bar and magnets are used to securely hold the microfluidic chip down onto the copper chiller plate, which is mounted to the Peltier plates. The SSR's, Figure 22 below, are the switches used to control the current flow to the Peltier plates; they are water cooled to increase stability and longevity, and are incased in an electronics enclosure to prevent short circuits. 


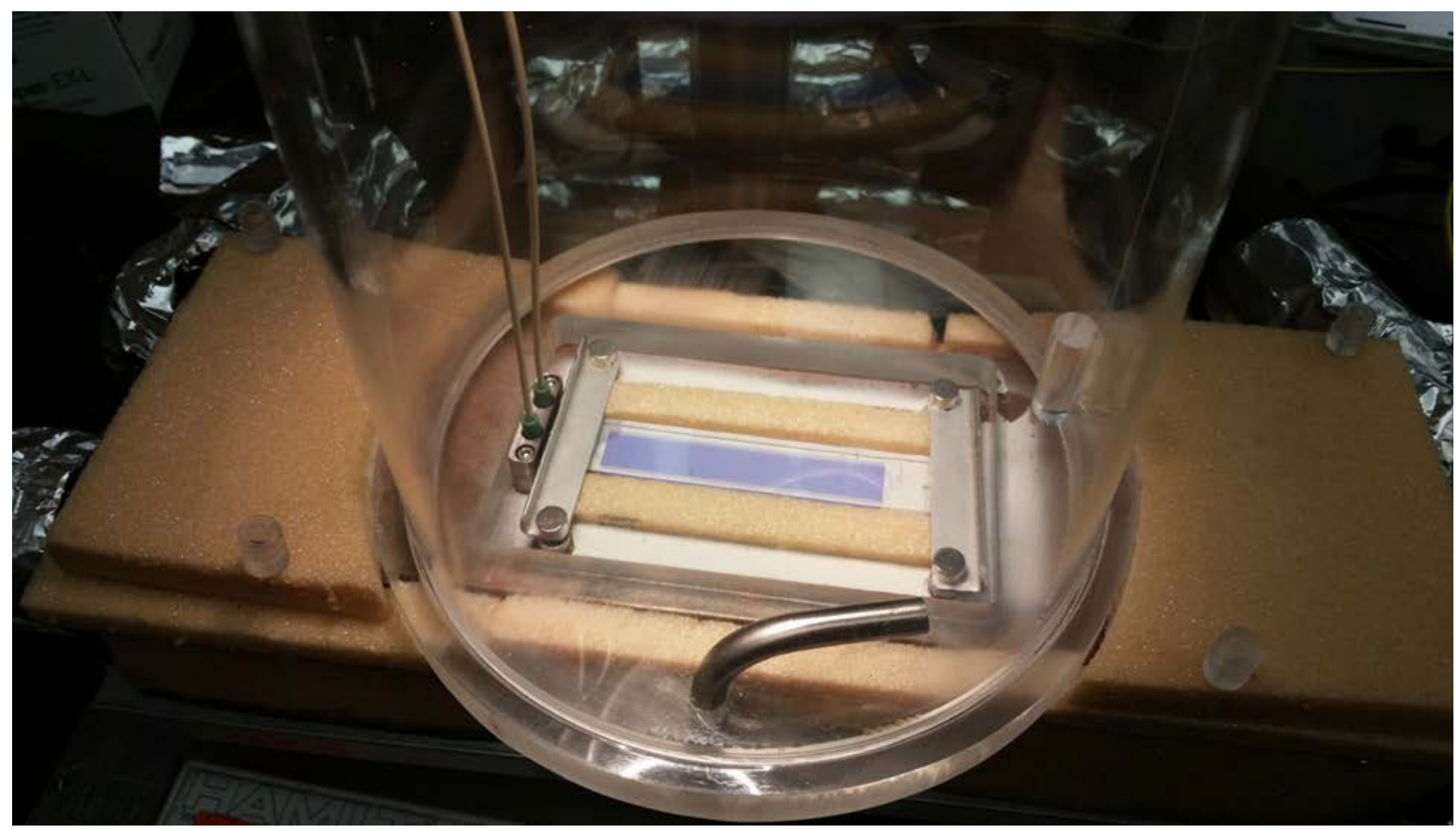

Figure 21. Chip flooded with dye stained THF/water solution in humidity control box with and inlet of dry air circulating within the polycarbonate chamber

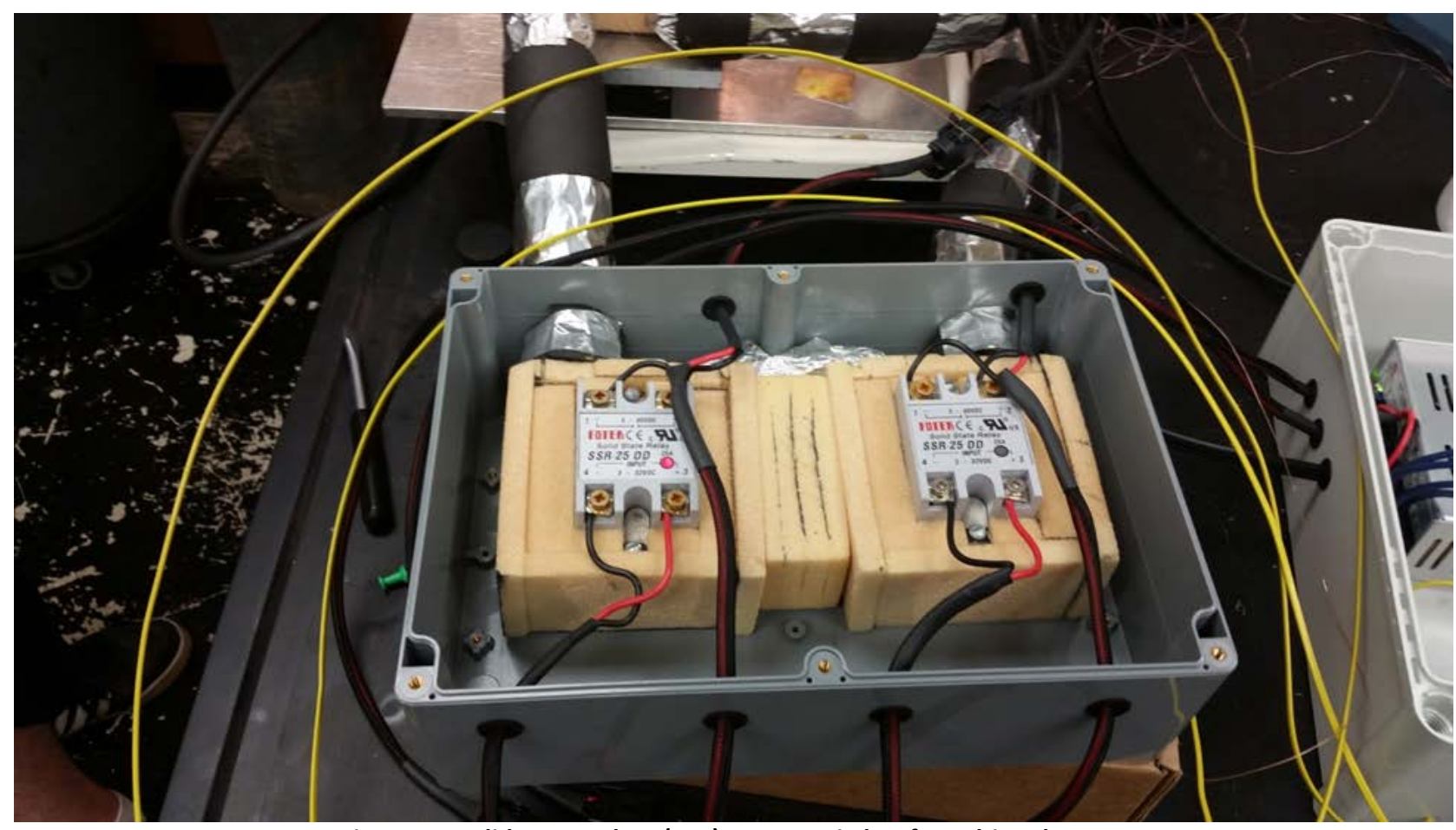

Figure 22. Solid State Relays (SSR) power switches for Peltier plates 


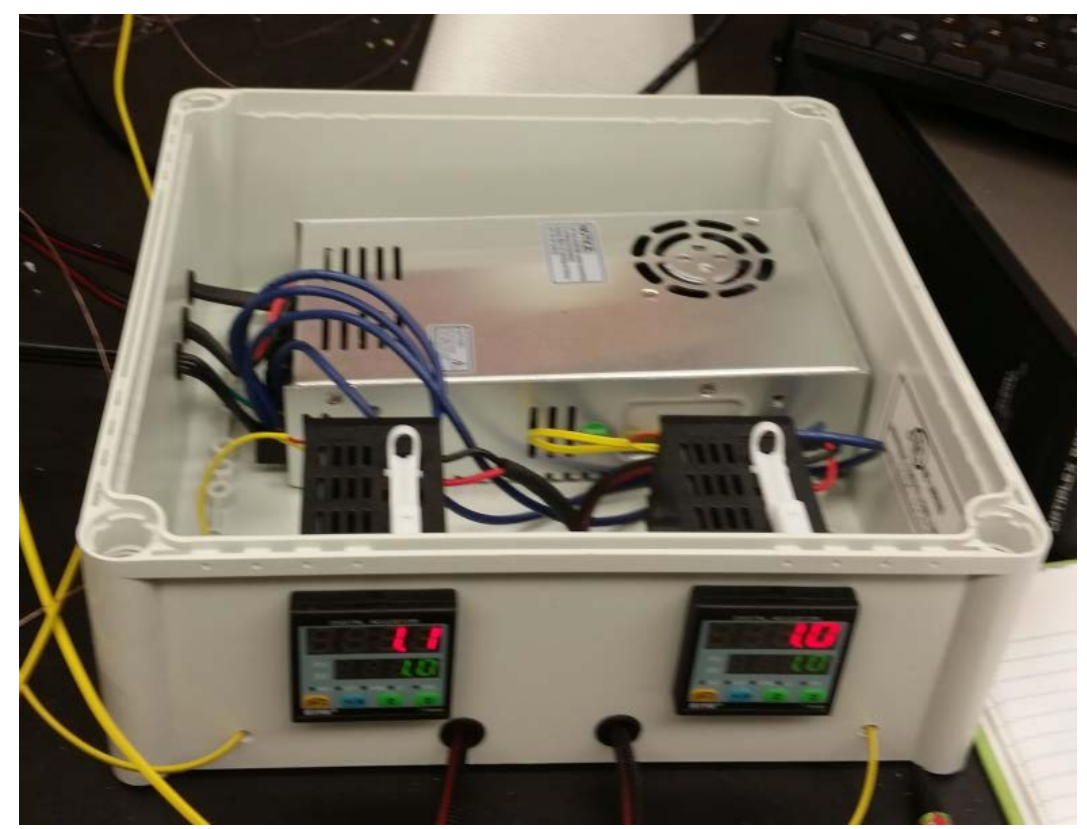

Figure 23. PID controllers for each Peltier plate

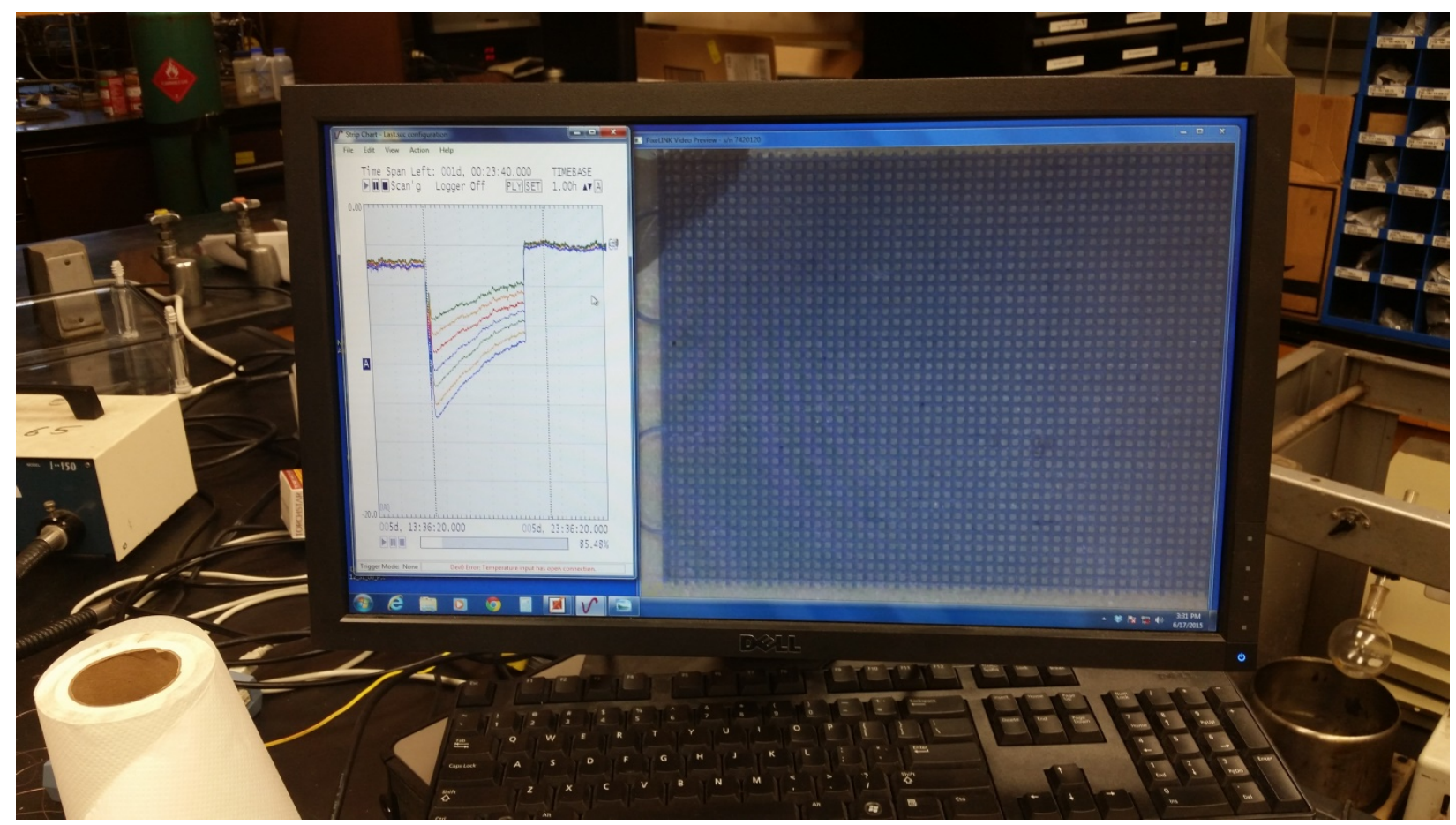

Figure 24. Live data logging of temperature across the chip and a live image of the chip

The PID controllers, Figure 23, and DC power supply are enclosed in an electrical box to prevent electrical exposure. Each Peltier plate is controlled by an individual PID controller that uses Kthermocouples to monitor the temperature at the Peltier plate face. Figure 24 , is a screen capture of the data logging computer. The left panel shows the temperature across the length of the microfluidic chip. The right panel is a live view of the microfluidic chip flooded with dyed THF/Water solution. 


\section{Results}

The biggest challenge faced in performing microfluidic permeability experiments was forming hydrate with the microfluidic chip using THF/Water solutions. THF/Water hydrates have a history of slow and troublesome formation. With the many variables that exist in the complex system of a microfluidic chip, numerous experiments were performed to determine the optimal conditions for hydrate formation.

\subsection{Experiment 1}

Water in a reservoir was pressurized with compressed air and this pressurized volume of water was used to flood the microfluidic chip. Once the microfluidic chip was completely flooded with water, a timer was started and $5 \mathrm{~g}$ of effluent was collected. This process was repeated at different system pressures, resulting in a plot of mass flow rate verses pressure. From this data a comparison to real world porous media can be performed using Darcy's Law. Figure 25, is the result obtained during preliminary testing of the microfluidic chips flow characteristics. The result of this data showed that the chip would provide a characteristically Darcy flow and that the microfluidic chip could be used as a porous media substitute.

\section{Microfluidic Chip - Darcy Flow Test}

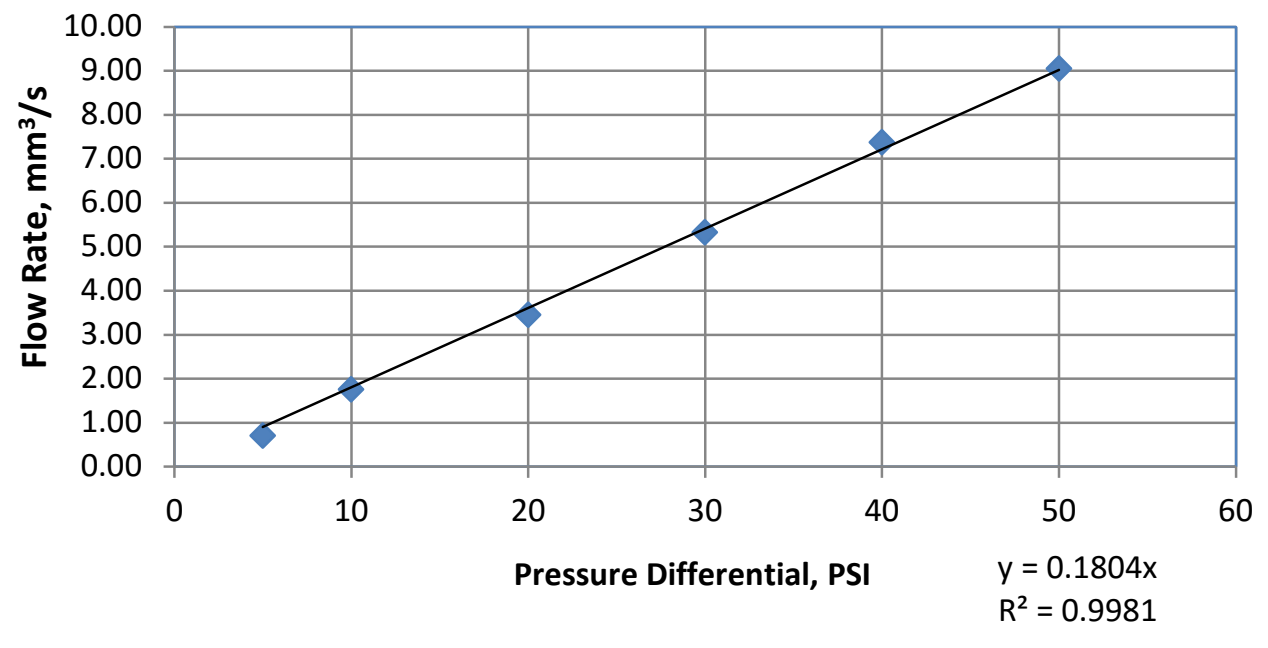

Figure 25. Plot of water permeability test, initial experiment to determine the flow characteristics of the microfluidic chip, performed at $25^{\circ} \mathrm{C}$

From this data $k_{\text {intrinsic }}$ can be calculated using equation 1 . First the cross sectional area must be calculated based on the dimensions of the microfluidic chip. With a width of $10 \mathrm{~mm}$ and a channel height of $110 \mu \mathrm{m}$ the cross sectional area $(\mathrm{A})$ is $1.1 \mathrm{~mm}^{2}$ and the porous media section has a length (L) of $60 \mathrm{~mm}$. Additionally the temperature of each experiment was held at $25^{\circ} \mathrm{C}$ so the viscosity $(\mu)$ of water is $.8937 \mathrm{mPa} \cdot \mathrm{s}$. Substituting each of the variables into equation 1 we can calculate $k_{\text {intrinsic }}$ for each pressure differential, Table 1, below. From here we find that $k_{\text {intrinsic }}$ has an average of 1.214 Darcy with a standard deviation of 0.112 . 
Table 1. Intrinsic Permeability of the microfluidic chip

\begin{tabular}{|ccc|}
\hline Pressure Differential, PSI & Volumetric Flow Rate, $\mathrm{mm}^{3} / \mathrm{s}$ & $k_{\text {intrinsic }}$, Darcy \\
\hline 50 & 9.044 & 1.279 \\
\hline 40 & 7.370 & 1.303 \\
\hline 30 & 5.321 & 1.254 \\
\hline 20 & 3.448 & 1.219 \\
\hline 10 & 1.748 & 1.236 \\
\hline 5 & 0.703 & 0.994 \\
\hline
\end{tabular}

\subsection{Experiment 2}

A 10\% THF/Water with $1 \%$ dye solution was made and used to flood the microfluidic chip. Starting with a temperature of $1^{\circ} \mathrm{C}$, the system was left to equilibrate for 1 week. In following weeks, the temperature was reduced in $0.5^{\circ} \mathrm{C}$ increments until the heat generated by the Peltier plates and SSR's overcame the chiller bath capacity. When this occurred, one Peltier plate was set to an "always on" setting and the other was adjusted to an "always off" setting. This adjustment provided an initial temperature of $-15^{\circ} \mathrm{C}$ but as the Peltier plates begin to heat the cooling bath a constant $-5^{\circ} \mathrm{C}$ could be maintained. The system was left in this condition for an additional two weeks with no visible change.

\subsection{Experiment 3}

The first experiment was repeated with $20 \%$ and $40 \%$ THF/Water $1 \%$ dye solutions. Additional hydrate formation stimulus was added by tapping on the microfluidic chip with a small plastic screwdriver. Additionally, the system was rapidly pressurized with up to $90 \mathrm{psi}$ and rapidly depressurized to atmospheric pressure (14 psi) repeatedly during each stage of the experiment. With no hydrate formation visualized with these experiments, a third experimental series was designed to find the conditions needed to form hydrate outside of the microfluidic chip. Table 2 lists the different combinations of temperature and pressure used to form hydrate along with an additional stimulus.

Table 2. Experiments performed to find optimal conditions for hydrate formation

\begin{tabular}{|c|c|c|c|c|}
\hline Temperature & Pressure & Time & Stimulus & Note \\
\hline $1{ }^{\circ} \mathrm{C}$ & Atmospheric & 1 week & & \multirow{14}{*}{$\begin{array}{c}\text { These test } \\
\text { were done } \\
\text { consecutively } \\
\text { with } 10 \% \\
\text { THF/Water } \\
\text { with } 1 \% \text { dye }\end{array}$} \\
\hline $0.5^{\circ} \mathrm{C}$ & Atmospheric & 1 week & & \\
\hline $0{ }^{\circ} \mathrm{C}$ & Atmospheric & 1 week & & \\
\hline$-0.5^{\circ} \mathrm{C}$ & Atmospheric & 1 week & & \\
\hline$-1{ }^{\circ} \mathrm{C}$ & Atmospheric & 1 week & & \\
\hline$-1.5^{\circ} \mathrm{C}$ & Atmospheric & 1 week & & \\
\hline$-2{ }^{\circ} \mathrm{C}$ & Atmospheric & 1 week & & \\
\hline$-2.5^{\circ} \mathrm{C}$ & Atmospheric & 1 week & & \\
\hline$-3^{\circ} \mathrm{C}$ & Atmospheric & 1week & & \\
\hline$-3.5^{\circ} \mathrm{C}$ & Atmospheric & 1 week & & \\
\hline$-4{ }^{\circ} \mathrm{C}$ & Atmospheric & 1week & & \\
\hline$-4.5^{\circ} \mathrm{C}$ & Atmospheric & 1 week & & \\
\hline$-5{ }^{\circ} \mathrm{C}$ & Atmospheric & 1week & & \\
\hline Temp fluctuations & Atmospheric & 3 days & & \\
\hline
\end{tabular}




\begin{tabular}{|c|c|c|c|c|}
\hline $\begin{array}{l}\text { due to Peltier plate } \\
\text { overheating }-10 \text { to }- \\
{ }^{\circ} \mathrm{C}\end{array}$ & & & & \\
\hline $1{ }^{\circ} \mathrm{C}$ & Atmospheric & 1 week & $\begin{array}{l}\text { Light tapping on chip pressurizing } \\
\text { to } 90 \text { psi and then depressurizing } \\
\text { to } 14 \mathrm{psi}\end{array}$ & \multirow{13}{*}{$\begin{array}{c}\text { These test } \\
\text { were done } \\
\text { consecutively } \\
\text { with } 20 \% \\
\text { THF/Water } \\
\text { and } 1 \% \text { dye }\end{array}$} \\
\hline $0.5{ }^{\circ} \mathrm{C}$ & Atmospheric & 1 week & $\begin{array}{l}\text { Light tapping on chip pressurizing } \\
\text { to } 90 \mathrm{psi} \text { and then depressurizing } \\
\text { to } 14 \mathrm{psi}\end{array}$ & \\
\hline $0{ }^{\circ} \mathrm{C}$ & Atmospheric & 1 week & $\begin{array}{l}\text { Light tapping on chip pressurizing } \\
\text { to } 90 \text { psi and then depressurizing } \\
\text { to } 14 \mathrm{psi}\end{array}$ & \\
\hline$-0.5^{\circ} \mathrm{C}$ & Atmospheric & 1 week & $\begin{array}{l}\text { Light tapping on chip pressurizing } \\
\text { to } 90 \text { psi and then depressurizing } \\
\text { to } 14 \mathrm{psi}\end{array}$ & \\
\hline$-1{ }^{\circ} \mathrm{C}$ & Atmospheric & 1 week & $\begin{array}{l}\text { Light tapping on chip pressurizing } \\
\text { to } 90 \text { psi and then depressurizing } \\
\text { to } 14 \mathrm{psi}\end{array}$ & \\
\hline$-1.5^{\circ} \mathrm{C}$ & Atmospheric & 1 week & $\begin{array}{l}\text { Light tapping on chip pressurizing } \\
\text { to } 90 \text { psi and then depressurizing } \\
\text { to } 14 \mathrm{psi}\end{array}$ & \\
\hline$-2{ }^{\circ} \mathrm{C}$ & Atmospheric & 1 week & $\begin{array}{l}\text { Light tapping on chip pressurizing } \\
\text { to } 90 \mathrm{psi} \text { and then depressurizing } \\
\text { to } 14 \mathrm{psi}\end{array}$ & \\
\hline$-2.5^{\circ} \mathrm{C}$ & Atmospheric & 1 week & $\begin{array}{l}\text { Light tapping on chip pressurizing } \\
\text { to } 90 \mathrm{psi} \text { and then depressurizing } \\
\text { to } 14 \mathrm{psi}\end{array}$ & \\
\hline$-3{ }^{\circ} \mathrm{C}$ & Atmospheric & 1week & $\begin{array}{l}\text { Light tapping on chip pressurizing } \\
\text { to } 90 \mathrm{psi} \text { and then depressurizing } \\
\text { to } 14 \mathrm{psi}\end{array}$ & \\
\hline$-3.5^{\circ} \mathrm{C}$ & Atmospheric & 1 week & $\begin{array}{l}\text { Light tapping on chip pressurizing } \\
\text { to } 90 \mathrm{psi} \text { and then depressurizing } \\
\text { to } 14 \mathrm{psi}\end{array}$ & \\
\hline$-4{ }^{\circ} \mathrm{C}$ & Atmospheric & 1week & $\begin{array}{l}\text { Light tapping on chip pressurizing } \\
\text { to } 90 \text { psi and then depressurizing } \\
\text { to } 14 \mathrm{psi}\end{array}$ & \\
\hline$-4.5^{\circ} \mathrm{C}$ & Atmospheric & 1 week & $\begin{array}{l}\text { Light tapping on chip pressurizing } \\
\text { to } 90 \mathrm{psi} \text { and then depressurizing } \\
\text { to } 14 \mathrm{psi}\end{array}$ & \\
\hline$-5^{\circ} \mathrm{C}$ & Atmospheric & 1week & $\begin{array}{l}\text { Light tapping on chip pressurizing } \\
\text { to } 90 \text { psi and then depressurizing } \\
\text { to } 14 \mathrm{psi}\end{array}$ & \\
\hline $\begin{array}{l}\text { Initial }-15{ }^{\circ} \mathrm{C} \text { held } \\
\text { steady at }-5{ }^{\circ} \mathrm{C}\end{array}$ & $\begin{array}{l}\text { Initial pressure } \\
50 \mathrm{psi}\end{array}$ & $\begin{array}{c}2.5 \\
\text { weeks }\end{array}$ & $\begin{array}{l}\text { Light tapping with pressure } \\
\text { reduced to } 14 \text { psi and returned to } \\
50 \text { psi } 4 \text { time/day }\end{array}$ & \\
\hline Initial $-15^{\circ} \mathrm{C}$ held & Initial pressure & 1 weeks & Light tapping with pressure & \\
\hline
\end{tabular}




\begin{tabular}{|cccc|}
\hline steady at $-5^{\circ} \mathrm{C}$ & $100 \mathrm{psi}$ & $\begin{array}{c}\text { reduced to } 14 \mathrm{psi} \text { and returned to } \\
100 \mathrm{psi} 4 \text { time/day }\end{array}$ \\
\hline $\begin{array}{c}\text { Initial }-15{ }^{\circ} \mathrm{C} \text { held } \\
\text { steady at }-5{ }^{\circ} \mathrm{C}\end{array}$ & $\begin{array}{c}\text { Initial pressure } \\
150 \mathrm{psi}\end{array}$ & 1 weeks & $\begin{array}{c}\text { Light tapping with pressure } \\
\text { reduced to } 14 \mathrm{psi} \text { and returned to } \\
150 \mathrm{psi} 4 \text { time/day }\end{array}$ \\
\hline $\begin{array}{c}\text { Initial }-15{ }^{\circ} \mathrm{C} \text { held } \\
\text { steady at }-5{ }^{\circ} \mathrm{C}\end{array}$ & $\begin{array}{c}\text { Initial pressure } \\
14 \text { psi }\end{array}$ & 2 weeks & $\begin{array}{r}\text { Light tapping with pressure } \\
\text { increased to } 150 \text { psi then reduced } \\
\text { to } 14 \text { psi } 2 \text { time/day }\end{array}$ \\
\hline
\end{tabular}

\subsection{Experiment Series 4}

A series of experiments were performed to examine the potential exclusion of dye from hydrate to make visualization easier. The first few experiments showed that some dye exclusion occurred, but the dye was only excluded from part of the solid. The primary question resulting from the dye exclusion experiments was, "Did dye exclusion confirm hydrate formation, or did the water simply freeze?" A subsequent experiment was conducted to see if water $+1 \%$ dye solution would freeze and exclude the dye. This experiment confirmed that frozen water would not contain the dye, Figure 26 . Thus, it will be important to maintain the system temperature within the hydrate stability zone and not approach the freezing point of the THF/Water solution.

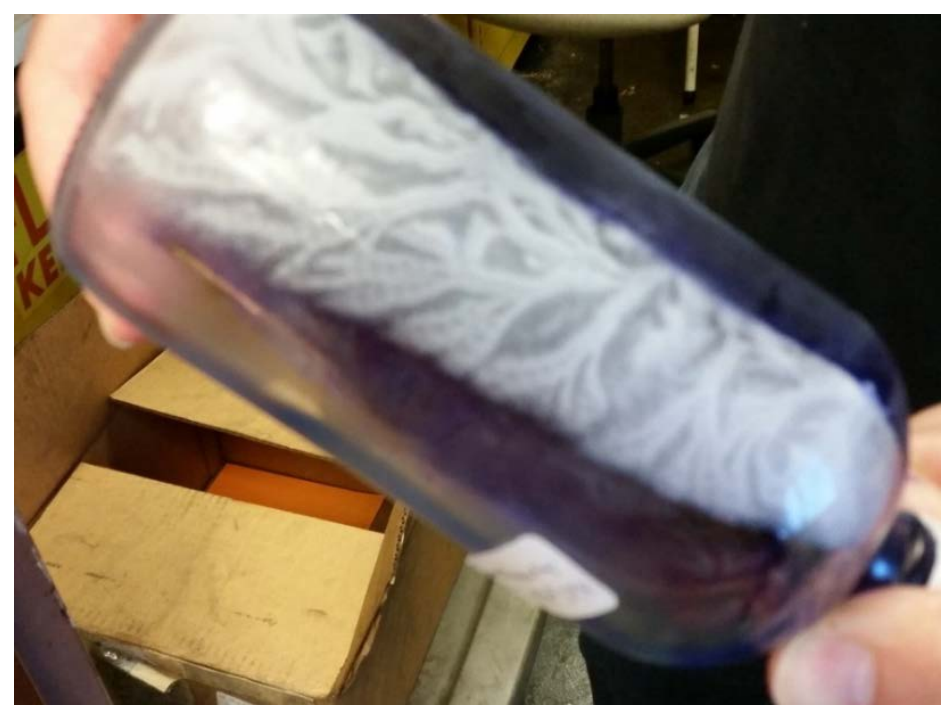

Figure 26. Frozen water crystals that have excluded the methyl blue dye

\subsection{Experiment Series 5}

Experiments were conducted to determine how the concentration of THF and dye affect the formation of hydrate. Three test tubes were filled with $10 \%(w: w)$ THF/Water solution; the first contained $0.1 \%$ dye, the second contained $1 \%$ dye, and the third contained no dye. The three test tubes were then suspended in a temperature controlled bath held at $0.5^{\circ} \mathrm{C}$ and checked periodically for crystal formation. The same preparation and testing was repeated for $20 \%$ and $40 \%$ THF/Water solutions, with the same 
amounts of dye added to the corresponding test tubes. The $40 \%$ THF/Water solution with $0.1 \%$ dye was the first to form hydrate, and it excluded the dye as expected. However, the $40 \%$ THF/Water solution with $1 \%$ dye also formed hydrate but did not exclude the dye, Figure 27 . No other solutions formed hydrate. The temperature was lowered to $-2.8^{\circ} \mathrm{C}$ and left for 72 hours to see if the remaining seven test tubes would form hydrate; they did not.

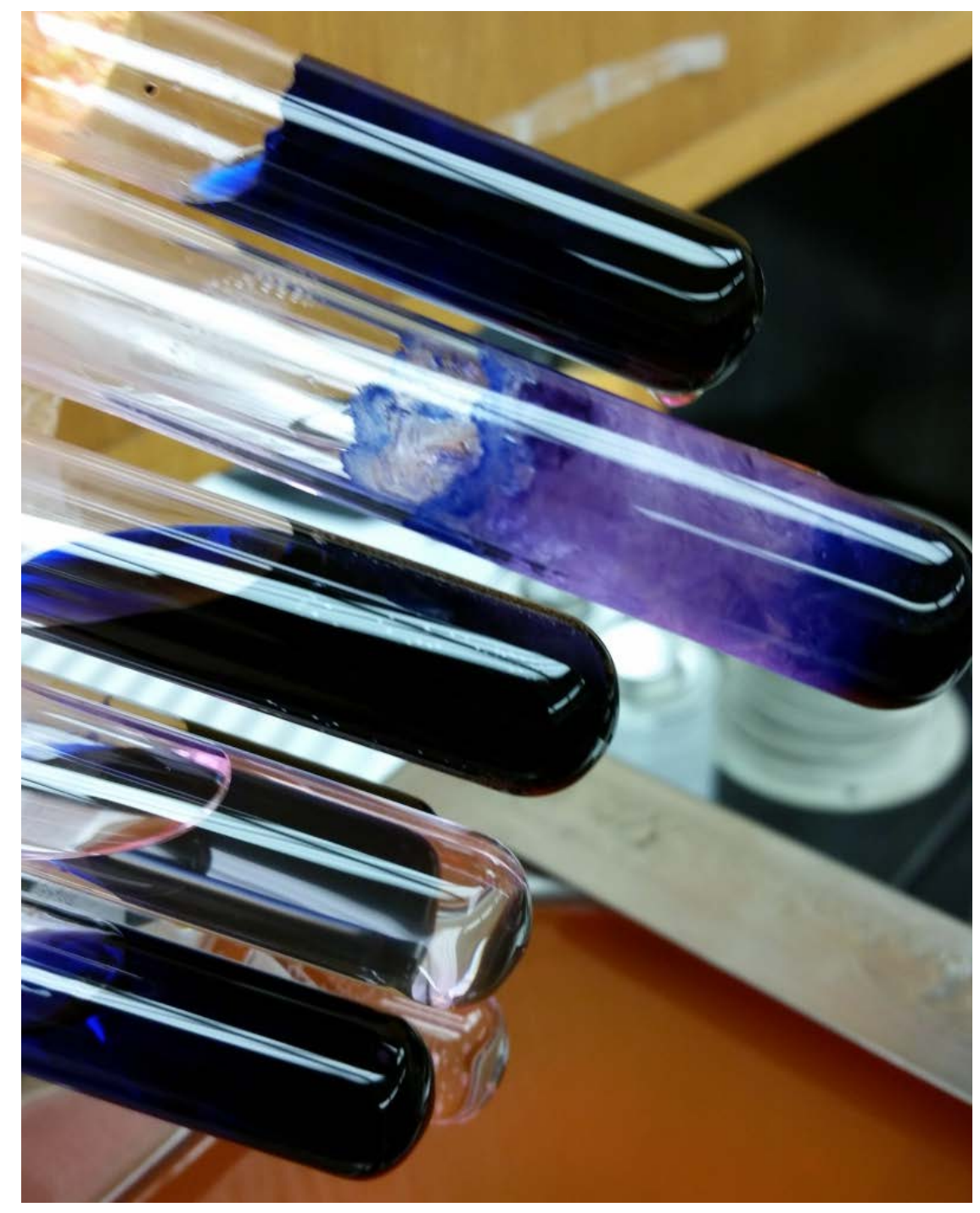

Figure 27. Test tube showing the formation of hydrate in a $40 \%$ THF/Water solution containing $\mathbf{0 . 1 \%}$ dye compared to other solutions that did not form hydrate

\subsection{Experimental Series 6}

The same solutions from the fourth experimental series were used once again but this time the test tubes were held at $-5^{\circ} \mathrm{C},-10^{\circ} \mathrm{C}$, and $-15^{\circ} \mathrm{C}$. Of note is that $-15^{\circ} \mathrm{C}$ was the lowest temperature obtainable with the current configuration within the temperature bath. The purpose of this experiment was to determine if extreme sub cooling would result in auto nucleation of hydrate in the test tubes. With all but two test tubes forming hydrate at $-15^{\circ} \mathrm{C}$ it was concluded that extreme sub cooling should work to induce hydrate formation with the microfluidic chip, Figure 28. 


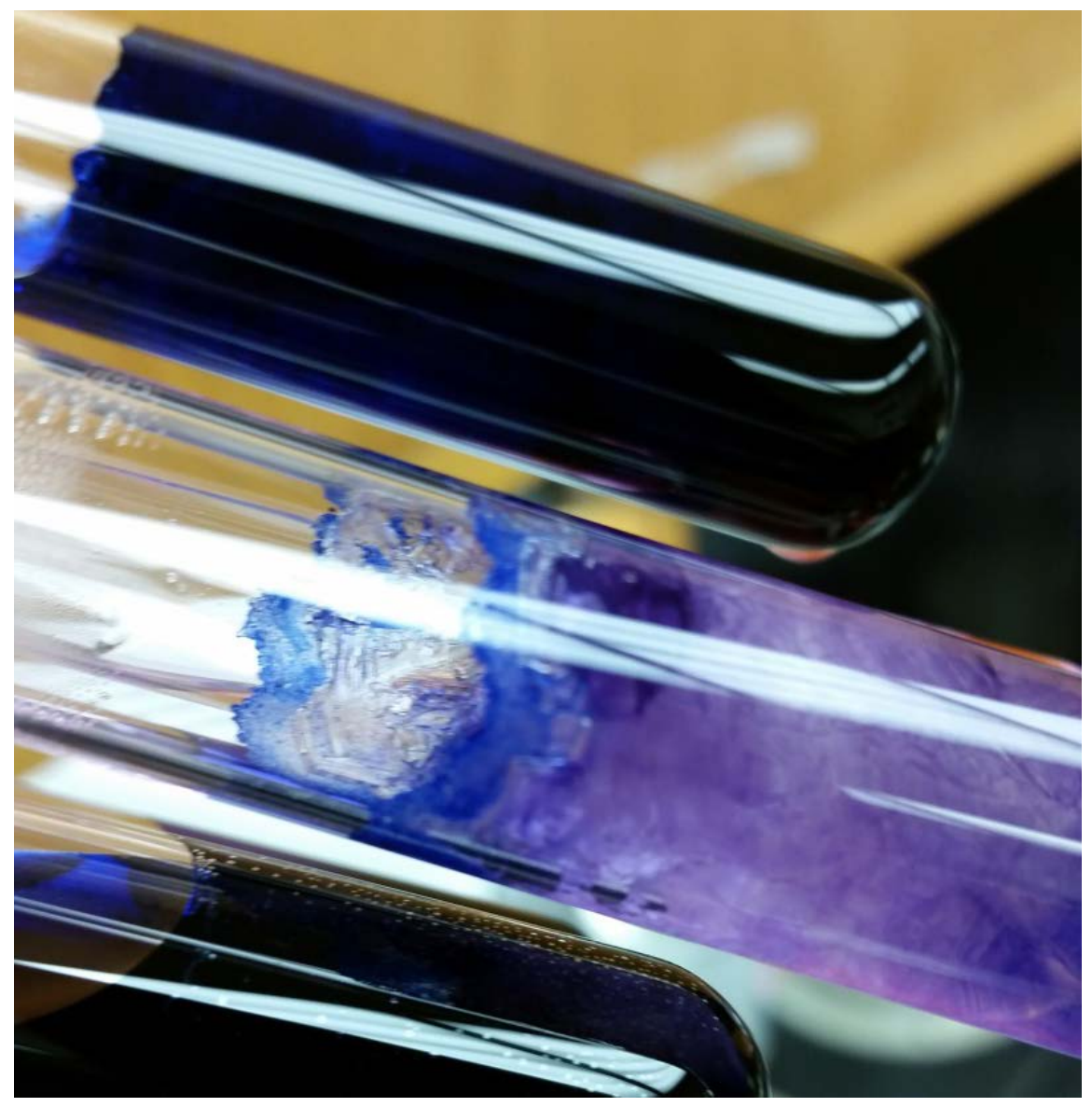

Figure 28. Close up of hydrate formed in two vials of $40 \%$ THF/Water solution. The top vial contains $1 \%$ dye not excluded and below that the vial contains $0.1 \%$ dye that is excluded.

\subsection{Experimental Series 7}

Formation of hydrate within the microfluidic chip was performed with a $20 \%$ THF/ Water solution with $1 \%$ dye. The chip was flooded, Figure 29 shows the even distribution of color, and then the temperature bath was set at $-15^{\circ} \mathrm{C}$ before turning on the Peltier plates. This was to prevent the chiller bath from overheating once the Peltier Plates were turned on due to heat soak. With the bath at its lowest operating temperature and the Peltier Plates activated the temperature dropped to $-25^{\circ} \mathrm{C}$. 


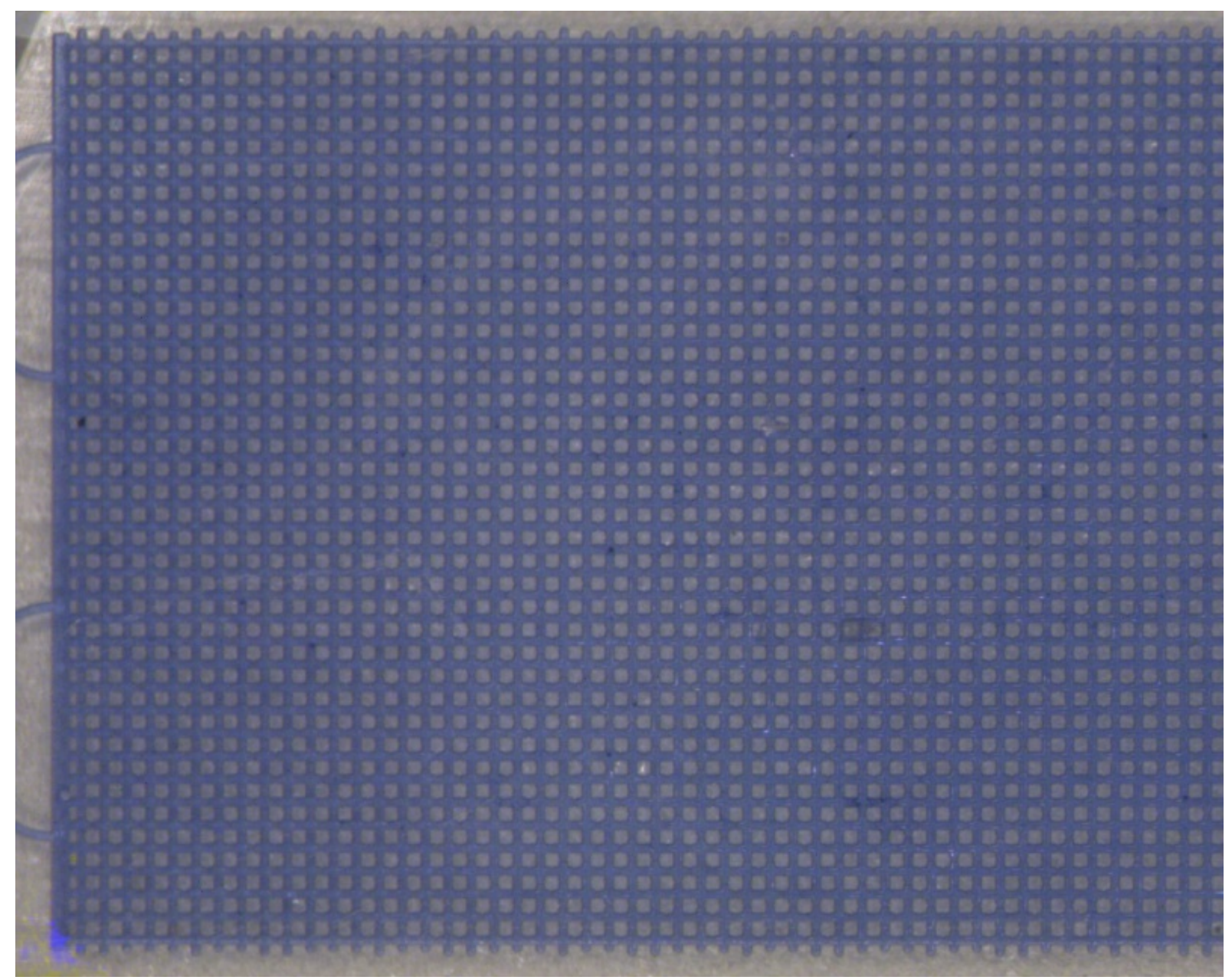

Figure 29. Completely flooded chip showing consistent dye distribution

With the new larger cooling bath the system was finally able to maintain this temperature for prolong periods. Over the course of a week the system was periodically examined for signs of hydrate formation. After 7 days of $-25^{\circ} \mathrm{C}$ the solid blue background began to show signs of changes as hydrate began to form. The system was left unaltered for an additional week until no additional changes appeared. Now the temperature was raised to $0.5^{\circ} \mathrm{C}$ to confirm that the visible changes observed were hydrate and not just ice formation. The system was left at $0.5^{\circ} \mathrm{C}$ for 3 days to allow the temperatures to equilibrate. At $0.5^{\circ} \mathrm{C}$ no changes in the appearance we can conclude that hydrate has been formed with in the chip, Figure 30 shows the changes from the uniform distribution of dye in Figure 29 to the hydrate formations that have excluded the dye. 


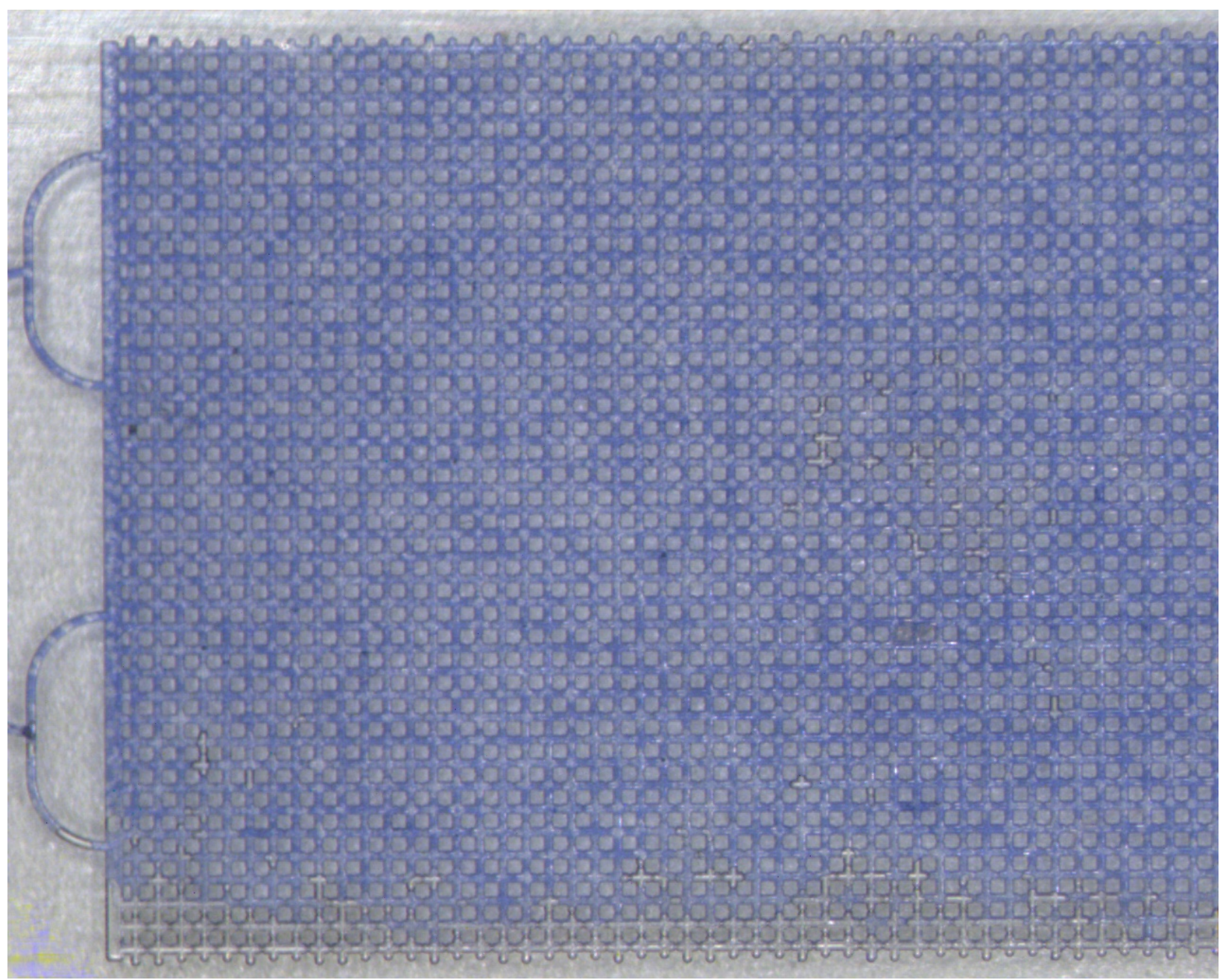

Figure 30. Microfluidic chip after hydrate formation 


\section{Observed Obstacles and Recomendations}

With the use of the microscope and camera to visualize the change in dye intensity has proven to be a difficult way of calculation the hydrate saturation. As the hydrate forms and excludes the dye the area in the chip becomes lighter in color, however until the area is completely filled with hydrate the dye rich liquid surrounds the hydrate producing a faint blue color. Analyzing the image with ImageJ using a histogram analysis of the intensity we can deduce the percent hydrate within the system. However this process does not verify the presence of hydrate only a visual change in color. To better image what is occurring within the microfluidic chip it is recommended that a confocal microscope or a CT scanner would provide more detail to what is occurring with the chip. Confocal microscopy could be used to image the entire height of the microfluidic channel producing a 3D image. This would allow for a more accurate determination of hydrate saturation as opposed to the 2D images from a standard microscope. CT scanning the microfluidic chip also provides a 3D image allowing for more accurate determination of hydrate saturation within the micro-channels.

Secondly once hydrate has formed within the chip the occurrence of hydrate formation in the inlet and outlets lead to difficulties in performing permeability studies. By the initial design of the cooling plate transferring heat across the full length and width of the chip it is impossible to prevent hydrate formation in the inlet and outlet. Spot heating is needed to melt the hydrate and once a flow field is induced the inlet and outlet should remain clear of hydrate. 


\section{References}

Bera B, Mitra SK, Kumar Gunda NS, Hassanizadeh SM, Karadimitriou NK. "Reservoir-on-a-Chip (ROC): A new paradigm in reservoir engineering." Lab on a Chip - Miniaturization for Chemistry and Biology. 2011;11(22):3785-92.

Berejnov, Viatcheslav, Ned Djilali, and David Sinton. "Lab-on-Chip Methodologies for the Study of Transport in Porous Media: Energy Applications." Lab on a Chip - Miniaturisation for Chemistry and Biology 8.5 (2008): 689-93.

Chen Y, Liang H, Song Y, Liu Y. "The Measurement of Permeability of Porous Media with Methane Hydrate". Petroleum Science and Technology. 2011;2010;29(1):79-87.

Dai, Sheng, and Yongkoo Seol. "Water Permeability in hydrate-bearing Sediments: A pore-scale Study."Geophysical Research Letters 41.12 (2014): 4176-84.

Darcy, H. "Les Fontaines Publiques de la ViUe de Dijon." Victor Dalmont, Paris, 1856.

Delli, Mohana L., and Jocelyn L. H. Grozic. "Prediction Performance of Permeability Models in GasHydrate-Bearing Sands." SPE Journal 18.2 (2013): 274-84.

Dolomite. "Porous Media Chip." Hertfordshire, United Kingdom, The Dolomite Centre Ltd. 2015, MAR-000047 v1.5

Feng H, Tomov S, Mahajan D, Kerkar PJ, K, Kleinberg R, Lindquist W. "Direct Observations of Three Dimensional Growth of Hydrates Hosted in Porous Media." Applied Physics Letters. 2009;95(2).

Haifeng Liang Yongchen Song Yu Liu Mingjun Yang Xing Huang. "Study of the Permeability Characteristics of Porous Media with Methane Hydrate by Pore Network Model." Journal of Natural Gas Chemistry 19.3 (2010): 255-60.

Head, K.H., and Epps, R.J.. Manual of Soil Laboratory Testing : Effective Stress Tests (3rd Edition). Dunbeath, Caithness, GBR: Whittles Publishing, 2014.

Ito T, Komatsu Y, Fujii T, Suzuki K, Egawa K, Nakatsuka Y, et al. "Lithological features of hydratebearing sediments and their relationship with gas hydrate saturation in the eastern Nankai Trough, Japan." Marine and Petroleum Geology. 2015;66:368-78.

Jin, Yusuke, Yoshihiro Konno, and Jiro Nagao. "Growth of Methane Clathrate Hydrates in Porous Media." Energy and Fuels 26.4 (2012): 2242-7.

Johnson A, Patil S, Dandekar A. "Experimental investigation of gas-water relative permeability for gas-hydrate-bearing sediments from the Mount Elbert Gas Hydrate Stratigraphic Test Well, Alaska North Slope." Marine and Petroleum Geology. 2011;28(2):419-26. 
Joseph, J., NSK Gunda, and SK Mitra. "On-Chip Porous Media: Porosity and Permeability Measurements." Chemical Engineering Science. 99 (2013): 274-83.

Katsuki, Daisuke, et al. "Visual Observation of Dissociation of Methane Hydrate Crystals in a Glass Micro Model: Production and Transfer of Methane." Journal of Applied Physics 104.8 (2008): 083514,083514-9.

Katsuki D, Ohmura R, Narita H, Ebinuma T. "Visual observation of dissociation of methane hydrate crystals in a glass micro model: Production and transfer of methane." Journal of Applied Physics. 2008;104(8):083514,083514-9.

King, Hobart. "Methane Hydrate: The world's largest natural gas resource is trapped beneath permafrost and ocean sediments" Geology.com. 27 Aug 2014. Geoscience News and Information. 15 Mar 2015 <http://geology.com/articles/methane-hydrates/>.

Kleinberg RL, Flaum C, Griffin DD, Brewer PG, Malby GE, Peltzer ET, Yesinowski JP. “Deep sea NMR: Methane hydrate growth habit in porous media and its relationship to hydraulic permeability, deposit accumulation, and submarine slope stability." Journal of Geophysical Research - Solid Earth. 2003;108(B10):2508,n/a.

Kneafsey T, Seol Y, Gupta A, Tomutsa L. "Permeability of Laboratory-Formed Methane-HydrateBearing Sand: Measurements and Observations Using X-Ray Computed Tomography." SPE Journal. 2011;16(1):78-94.

Kumar A, Maini B, Bishnoi PR, Clarke M, Zatsepina O, Srinivasan S. "Experimental determination of permeability in the presence of hydrates and its effect on the dissociation characteristics of gas hydrates in porous media." Journal of Petroleum Science and Engineering. 2010;70(1):114-22.

Lee, M. W., and T. S. Collett. "Gas Hydrate Saturations Estimated from Fractured Reservoir at Site NGHP-01-10, Krishna-Godavari Basin, India." Journal of Geophysical Research - Solid Earth 114.B7 (2009): B07102.

Lee, M. W., and T. S. Collett. "In-Situ Gas Hydrate Hydrate Saturation Estimated from various Well Logs at the Mount Elbert Gas Hydrate Stratigraphic Test Well, Alaska North Slope." Marine and Petroleum Geology 28.2 (2011): 439-49.

Liang, Haifeng, Yongchen Song, Yu Liu, Mingjun Yang, and Xing Huang. "Study of the Permeability Characteristics of Porous Media with Methane Hydrate by Pore Network Model." Journal of Natural Gas Chemistry 19.3 (2010): 255-60.

Linga P, Haligva C, Nam S, Ripmeester J, Englezos P. "Gas Hydrate Formation in a Variable Volume Bed of Silica Sand Particles." Energy \& Fuels. 2009;23:5496-507

Makogon, Yuri F. "Natural Gas Hydrates - A Promising Source of Energy." Journal of Natural Gas Science and Engineering 2.1 (2010): 49-59. 
Myshakin E, Gaddipati M, Rose K, Anderson B. "Numerical simulations of depressurization-induced gas production from gas hydrate reservoirs at the Walker Ridge 313 site, northern Gulf of Mexico." Marine and Petroleum Geology. 2012;2011;34(1):169-85.

Ohmura R, Katsuki D, Narita H, Ebinuma T. "Visual observation of dissociation of methane hydrate crystals in a glass micro model: Production and transfer of methane." Journal of Applied Physics. 2008;104(8):083514,083514-9.

Ryan, Terrence R., and West Virginia University. "Effect of Sediment Composition on the Uniformity of Experimentally-Formed Methane Hydrate". Morgantown, W. Va: West Virginia University Libraries, 2012.

Sakamoto Y, Komai T, Miyazaki K, Tenma N, Yamaguchi T, Zyvoloski G. "Laboratory-Scale Experiments of the Methane Hydrate Dissociation Process in a Porous Media and Numerical Study for the Estimation of Permeability in Methane Hydrate Reservoir." Journal of Thermodynamics. 2010;2010:1-13.

Sloan, E. Dendy, and Carolyn A. Koh. "Clathrate Hydrates of Natural Gases. "3rd; 3. ed. 119.; 119 Vol. Boca Raton, FL: CRC Press, 2008.

Spangenberg E. "Modeling of the influence of gas hydrate content on the electrical properties of porous sediments." Journal of Geophysical Research-Solid Earth. 2001;106(B4):6535-48.

Tohidi B, Anderson R, Clennell MB, Burgass RW, Biderkab AB. "Visual observation of gas-hydrate formation and dissociation in synthetic porous media by means of glass micromodels." Geology. 2001;29(9):867-70.

Ueno H, Akiba H, Akatsu S, Ohmura R. "Crystal growth of clathrate hydrates formed with methane + carbon dioxide mixed gas at the gas/liquid interface and in liquid water." New Journal of Chemistry. 2015;39(11):8254-62.

Winters W, Walker M, Hunter R, Collett T, Boswell R, Rose K, et al. "Physical properties of sediment from the Mount Elbert Gas Hydrate Stratigraphic Test Well, Alaska North Slope." Marine and Petroleum Geology. 2011;28(2):361-80. 